\title{
USM3D Unstructured Grid Solutions for CAWAPI at NASA LaRC
}

\author{
John E. Lamar* and Khaled S. Abdol-Hamid \\ NASA Langley Research Center, Hampton, VA 23681-2199
}

\begin{abstract}
In support the Cranked Arrow Wing Aerodynamic Project International (CAWAPI) - to improve the Technology Readiness Level of flow solvers by comparing results with measured F-16XL-1 flight data, NASA Langley employed the TetrUSS unstructured grid solver, USM3D, to obtain solutions for all seven flight conditions of interest. A newly available solver version that incorporates a number of turbulence models, including the two-equation linear and non-linear k- $\varepsilon$, was used in this study. As a first test, a choice was made to utilize only a single grid resolution with the solver for the simulation of the different flight conditions. Comparisons are presented with three turbulence models in USM3D, flight data for surface pressure, boundary-layer profiles, and skin-friction results, as well as limited predictions from other solvers. A result of these comparisons is that the USM3D solver can be used in an engineering environment to predict flow physics on a complex configuration at flight Reynolds numbers with a two-equation linear $k-\varepsilon$ turbulence model.
\end{abstract}

\section{Nomenclature}

AVT

BL

B.L.

CAWAPI

CFD

CLF3D

CLF3D:BL-DS

$\mathrm{C}_{\mathrm{p}}$

$\mathrm{c}_{\mathrm{f}}$

FC

FS

F-16XL-1

I,j,k

LaRC

LE

$\mathrm{M}_{\infty}$

PAB3D

RANS

RTO

$\mathrm{R}_{\mathrm{n}}$ TetrUSS

SA

SST

USM3D

WL

iges

$\mathrm{x} / \mathrm{c}$

$\mathrm{y}^{+}$
Applied Vehicle Technology (one of seven technical panels within the RTO)

butt line on airplane, in., positive on right wing (See fig. 1)

boundary layer

Cranked Arrow Wing Aerodynamics Project International

Computational Fluid Dynamics

name of structured flow solver developed at NASA Langley

CFL3D structured flow solver with the Baldwin-Lomax Degani-Schiff turbulence model

static-pressure coefficient

local skin friction coefficient

Flight Condition (See Table 1 and 2)

fuselage station on airplane, in., positive aft (See fig. 1)

An extensively modified version of the single-seat F-16A airplane which is longer and has a cranked arrow wing instead of a trapezoidal wing with leading-edge strake

grid indices

Langley Research Center

leading edge

free stream Mach number

name of structured flow solver developed at NASA Langley

Reynolds Averaged Navier Stokes

Research and Technology Organization - scientific arm of NATO

Reynolds number, based on airplane reference chord of $24.7 \mathrm{ft}$

Tetrahedral Unstructured Software System

Spalart-Allmaras turbulence model

Shear-Stress Transport

name of Unstructured Grid Flow Solver for both Euler and Navier Stokes equations developed at

NASA Langley and component of TetRUSS

waterline on airplane, in., positive up (See fig. 1)

Initial Graphics Exchange Specifications $\rightarrow$ - geometry descriptor

fractional distance along the local chord, positive aft

Reynolds number like term for flat-plate turbulent boundary layer (Ref.1)

* CAWAP Principal Investigator, Configuration Aerodynamics Branch, MS 499, Associate Fellow AIAA

Senior Research Scientist, Configuration Aerodynamics Branch, MS 499, Associate Fellow AIAA 
$\alpha$

$\beta$

$2 \mathrm{y} / \mathrm{b}_{1}$ angle of attack, deg

angle of side-slip, deg

fractional distance along the wing local semispan, positive toward the right wing tip

\section{Introduction}

Researchers at the NASA Langley Research Center (LaRC) performed a highly restrictive study with the flow solver portion of the NASA Tetrahedal Unstructured Software System ${ }^{2}$ (TetrUSS) - USM3D - in order to predict the flow physics on the F-16XL-1 airplane (See fig.1). The Flight Conditions (FCs) (See Tables 1 and 2) chosen for study were those of interest to the Cranked Arrow Wing Aerodynamics Project International (CAWAPI) facet $^{3}$ of the RTO/AVT-113 task group entitled "Understanding and Modeling Vortical Flows to Improve the Technology Readiness Level for Military Aircraft". This solver was chosen because it is a robust, accurate, wellvalidated Computational Fluid Dynamics (CFD) tool developed by resident in-house experts for use in a variety of flow physics and applied aerodynamics problems. Moreover, TetrUSS and/or the USM3D solver have won several awards, including: the competition in 1996 and 2004 for 'NASA Software of the Year'; recognition for its speed and accuracy of execution based on formulation at a 1989 NASA LaRC sponsored CFD unstructured grid solver workshop; and an 'Apple Design Award/Best OS X Scientific Computing Solution/Reno 2004'.

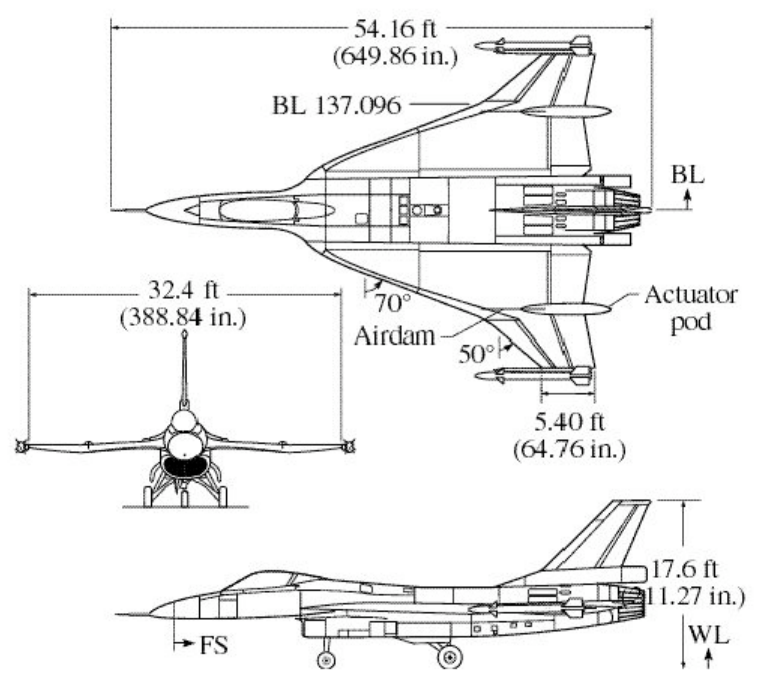

(a) Three-view drawing; linear dimensions in ft. (in.).

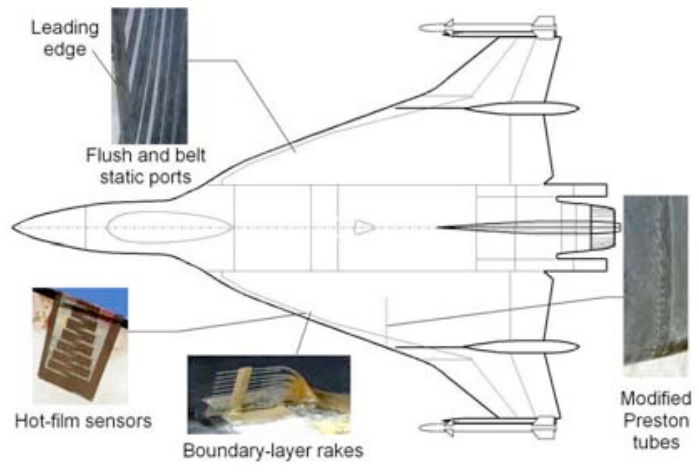

(b) Pressure instrumentation layout.

Figure 1. F-16XL-1 airplane drawing and pressure instrumentation layout.

A new version of USM3D has recently become available with additional turbulence models beyond the standard Spalart-Allmaras (SA); these include the two-equation linear and non-linear (Algebraic Reynolds Stress Model) k- $\varepsilon$ models. A series of classic flows such as; flat-plate, 2-D airfoil, 3-D wing-body, jet and other flows, have already been studied with this new version. The F-16XL-1, as a full airplane, provides an opportunity to extend and to understand the ability of this class of turbulence models to represent the flow physics around a complex configuration and this paper reports on the restrictive study, a first step.

The process employed here is to initially generate solutions at one vortical flow FC $-\mathrm{FC} 46\left(\mathrm{M}_{\infty}=0.527\right.$, $\left.\alpha=10.4^{\circ}, \mathrm{R}_{\mathrm{n}}=46.9 \times 10^{6}\right)-$ and one transonic flow FC $-\mathrm{FC70}\left(\mathrm{M}_{\infty}=0.97, \alpha=4.37^{\circ}, \mathrm{R}_{\mathrm{n}}=88.77 \mathrm{X} 10^{6}\right)-\mathrm{using}$ multiple turbulence models; then based on these comparisons with measured flight data ${ }^{4}$ down-select to a turbulence model for the other five FCs, as resources would not permit obtaining solutions at all FCs with all turbulence models. This was not an exhaustive study and really represents an approach one would use in an engineering environment. To emphasize the last point, all solutions were also obtained on a common unstructured grid - the baseline one - developed at LaRC specifically for FC19 $\left(\mathrm{M}_{\infty}=0.36, \alpha=11.85^{\circ}, \mathrm{R}_{\mathrm{n}}=46.8 \mathrm{X10^{6 }}\right) \mathrm{with}^{\mathrm{a}} \mathrm{y}^{+} \sim 1$. $(\mathrm{See}$ Ref. 5 for a description of the cooperative development of unstructured grids.) This choice was deliberate and was done, in part, to examine the limits of this robust solver with non-optimized grids at various FCs in which different flow physics dominate. For example, it is known ${ }^{6}$ that grid adaptation in the flow-field can be very important for 
votical flows, yet even the baseline grid - developed for a vortical flow FC - made no provision for such adaptation. Lastly, the paper provides a description of the solver; and comparisons with previous CFD solutions ${ }^{4}$ and those of $\mathrm{PAB} \mathrm{D}^{7}$, a structured grid flow solver at LaRC, for surface pressures, boundary-layer profiles and skin-friction distribution.

\section{A. Description}

\section{Solver description and application to CAWAPI}

The basic description of the USM3D flow solver with emphasis on the CAWAPI application is as follows: (1) Domain discretization - unstructured tetrahedral, cell centered, finite volume; (2) Physical modeling - RANS, one equation SA, two-equation Menter SST, two-equation linear and non-linear k- $\varepsilon$ models; (3) Space differencing Roe's flux-differnce splitting (FDS), Advection Upstream Splitting Method (AUSM), Flux Vector Splitting (FVS), and Harten, Lax and van Leer with contact restoration (HLLC); (4) Boundary conditions - engine inlet/outlet; (5) Steady state driver - Implicit scheme; (6) Time accurate scheme - Dual time stepping Newton method; (7) Grid used - Tetrahedral grid 16,161,959 cells for symmetrical FCs on half-airplane with center-line plane of symmetry imposed, and 32,323,918 cells for full airplane at sideslip; and (8) Special features - Static aero/structural coupling, solid and deforming grid motion, Overset Chimera grids, and 6 Degree Of Freedom motion.

Regarding grids, the USM3D solver used a minimum of $16,161,959$ cells. Solutions with it are compared with selected results from two LaRC structured solvers, PAB3 $\mathrm{D}^{7}$ using a linear version of the two-equation linear $\mathrm{k}-\varepsilon$ turbulence model and $\sim 20$ million cells and CFL3D ${ }^{4}$. The CFL3D solver used the Baldwin-Lomax with the Degani-Schiff turbulence model (in the $j-k$ directions) on a multi-block, patched grid $(1,372,096$ cells) with the "wall function" option because the $\mathrm{y}^{+} \sim 82^{4}$. [The figure captions refer to these results as CFL3D:BL-DS.] All codes compared in this paper are cell centered formulated and the wall function option was not used for any of the USM3D solutions reported here.

\section{B. Engine modeling, flight conditions, and computers used}

The F-16XL-1 airplane engine was modelled in the code by using the specific boundary condition types, i.e., engine intake or exhaust, and the associated values of temperature, pressure (or a ratio of that to the free-stream value) along with Mach number at the inlet and exhaust/mixing-plane for each FC (See Table $2^{3}$ ).

Table 1. Seven Flight Conditions to be Examined.

\begin{tabular}{|c|c|c|c|c|}
\hline Flight Condition & Actual Mach No. & $\begin{array}{c}\text { Actual } \boldsymbol{\alpha}, \\
\text { degs }\end{array}$ & $\begin{array}{c}\text { Actual } \boldsymbol{\beta}, \\
\mathbf{d e g s}\end{array}$ & Actual Reynolds No. \\
\hline FC7 & 0.304 & 11.89 & -0.133 & $44.4 \mathrm{E}+06$ \\
\hline FC19 & 0.36 & 11.85 & +0.612 & $46.8 \mathrm{E}+06$ \\
\hline FC46 & 0.527 & 10.4 & +0.684 & $46.9 \mathrm{E}+06$ \\
\hline FC70 & 0.97 & 4.37 & +0.310 & $88.77 \mathrm{E}+06$ \\
\hline FC25 & 0.242 & 19.84 & 0.725 & $32.22 \mathrm{E}+06$ \\
\hline FC50 & 0.434 & 13.56 & +5.31 & $39.41 \mathrm{E}+06$ \\
\hline FC51 & 0.441 & 12.89 & -4.58 & $38.95 \mathrm{E}+06$ \\
\hline
\end{tabular}


Table 2. Associated Engine Parameters* for these Flight Conditions.

\begin{tabular}{|c|c|c|c|c|c|c|c|c|}
\hline $\begin{array}{c}\text { Flight } \\
\text { Condition }\end{array}$ & $\begin{array}{c}\text { Free } \\
\text { Stream } \\
\text { Altitude, } \\
\mathbf{f t}\end{array}$ & $\begin{array}{c}\text { Free } \\
\text { Stream } \\
\text { Mach }\end{array}$ & $\begin{array}{c}\text { Inlet Duct } \\
\text { Exit Static } \\
\text { Temp., degs } \\
\mathbf{R}\end{array}$ & $\begin{array}{c}\text { Inlet Duct } \\
\text { Exit Static } \\
\text { Press., psia }\end{array}$ & $\begin{array}{c}\text { Inlet Duct } \\
\text { Exit } \\
\text { Velocity, } \\
\mathbf{f t / s e c}\end{array}$ & $\begin{array}{c}\text { Inlet } \\
\text { Duct } \\
\text { Exit } \\
\text { Mach }\end{array}$ & $\begin{array}{c}\text { Mixing } \\
\text { Plane } \\
\text { Total } \\
\text { Temp., } \\
\text { degs R }\end{array}$ & $\begin{array}{c}\text { Mixing } \\
\text { Plane } \\
\text { Total } \\
\text { Press., } \\
\text { psia }\end{array}$ \\
\hline FC7 & 5000 & 0.304 & 498 & 11 & 379.6 & 0.347 & 1050 & 23 \\
\hline FC19 & 10000 & 0.36 & 485.8 & 10.2 & 345.8 & 0.32 & 1050 & 21.5 \\
\hline FC46 & 24000 & 0.527 & 443.6 & 5.85 & 404.3 & 0.39 & 1045 & 14.8 \\
\hline FC70 & 22300 & 0.97 & 519 & 10.65 & 464.7 & 0.416 & 1200 & 30 \\
\hline FC25 & 10000 & 0.242 & 470.1 & 8.72 & 474.8 & 0.447 & 1209 & 26.3 \\
\hline FC50 & 24000 & 0.434 & 440 & 5.16 & 483.3 & 0.47 & 1154 & 16.95 \\
\hline FC51 & 24000 & 0.441 & 431.8 & 5.19 & 468.6 & 0.46 & 1146 & 16.74 \\
\hline
\end{tabular}

*The numbers in this table do not represent any particular engine.

Most of the solutions reported here were obtained on the Columbia high-speed cluster at NASA Ames using 128 processors, but a few solutions were obtained on the Langley PC/Linux cluster using 40 processors. Solution times ranged from 18 to 36 hours on the evolving Columbia cluster, depending on whether the FC was for symmetrical or asymmetrical configuration, to 52 hours on the PC/Linux cluster for a symmetrical configuration.

\section{Convergence histories}

The convergence history plots for the solutions reported here are shown in the appendix and labeled Fig. A1. These figures show that all solutions converged to a three-order reduction in the log residual-ratio on this grid.

\section{Turbulence model studies: results and discussion}

$$
\text { A. } \quad \text { FC46 }\left(M_{\infty}=0.527, \alpha=10.4^{\circ}, R_{n}=46.9 \times 10^{6}\right)\left[\text { Flight at } \beta<1^{\circ} \text {, modeled as } \beta=0^{\circ}\right. \text { ] }
$$

There is a pronounced effect of turbulence models on the vortical flow predictability at FC46, as seen in Fig. 2. Whereas, the effect of vortical flows on the upper surface $C_{p}$ is often better seen in the spanwise plots (Figs. 2(h)-2(n)) than from the chordwise (Figs. 2(a)-2(g)) ones, the presentation order of reference 4 is followed here which has the chordwise plots first. Fig. 2(o) shows measured right-wing surface $C_{p}$, also mirrored about the center-line, with both the two-equation linear and non-linear k- $\varepsilon$ model used in the USM3D solver. 


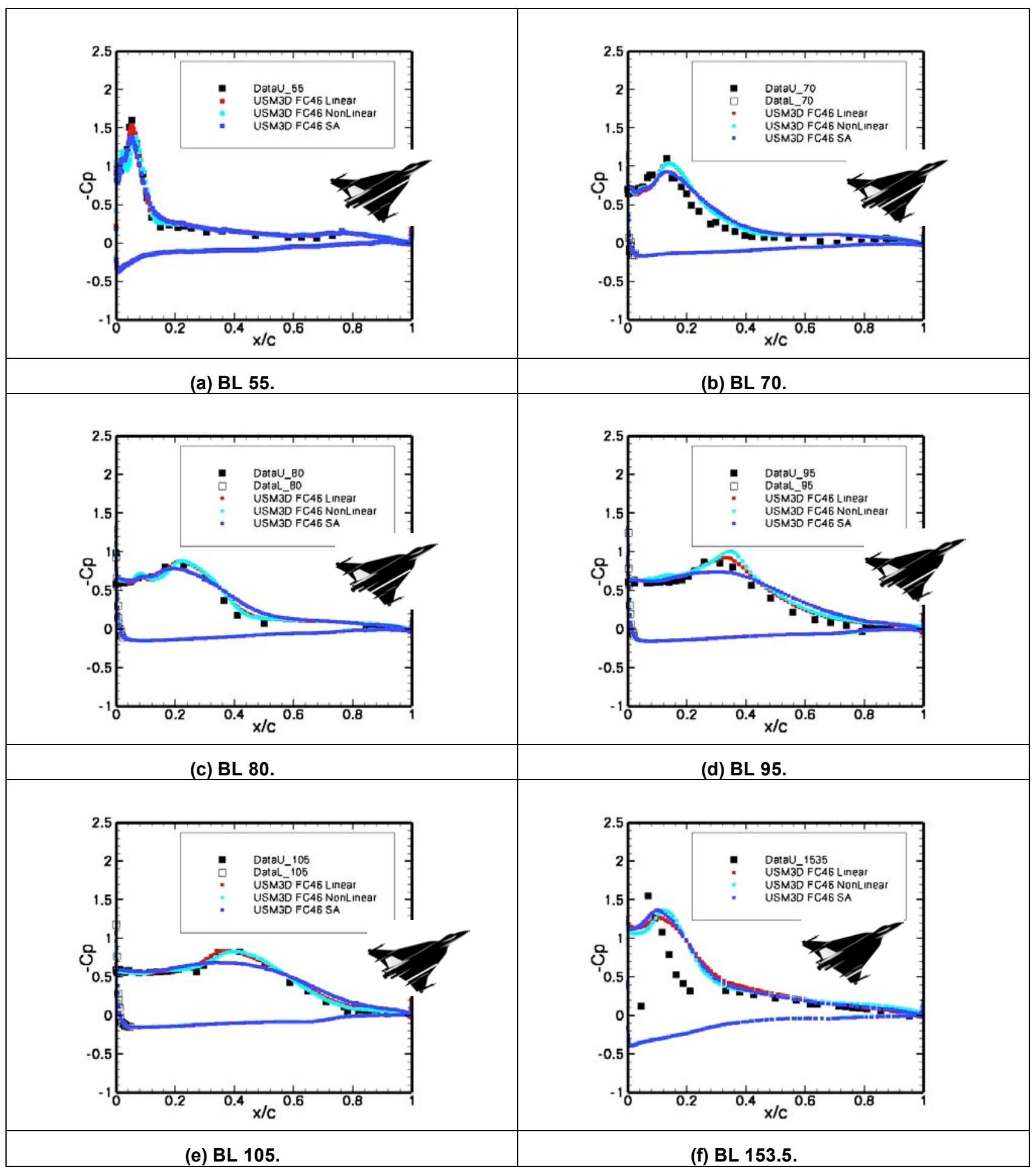

Figure 2. Effect of turbulence modeling on $C_{p}$ from USM3D at FC46 $\left(M_{\infty}=0.527, \alpha=10.4^{\circ}, R_{n}=46.9 \times 10^{6}\right)$; Data from Ref. 4. 


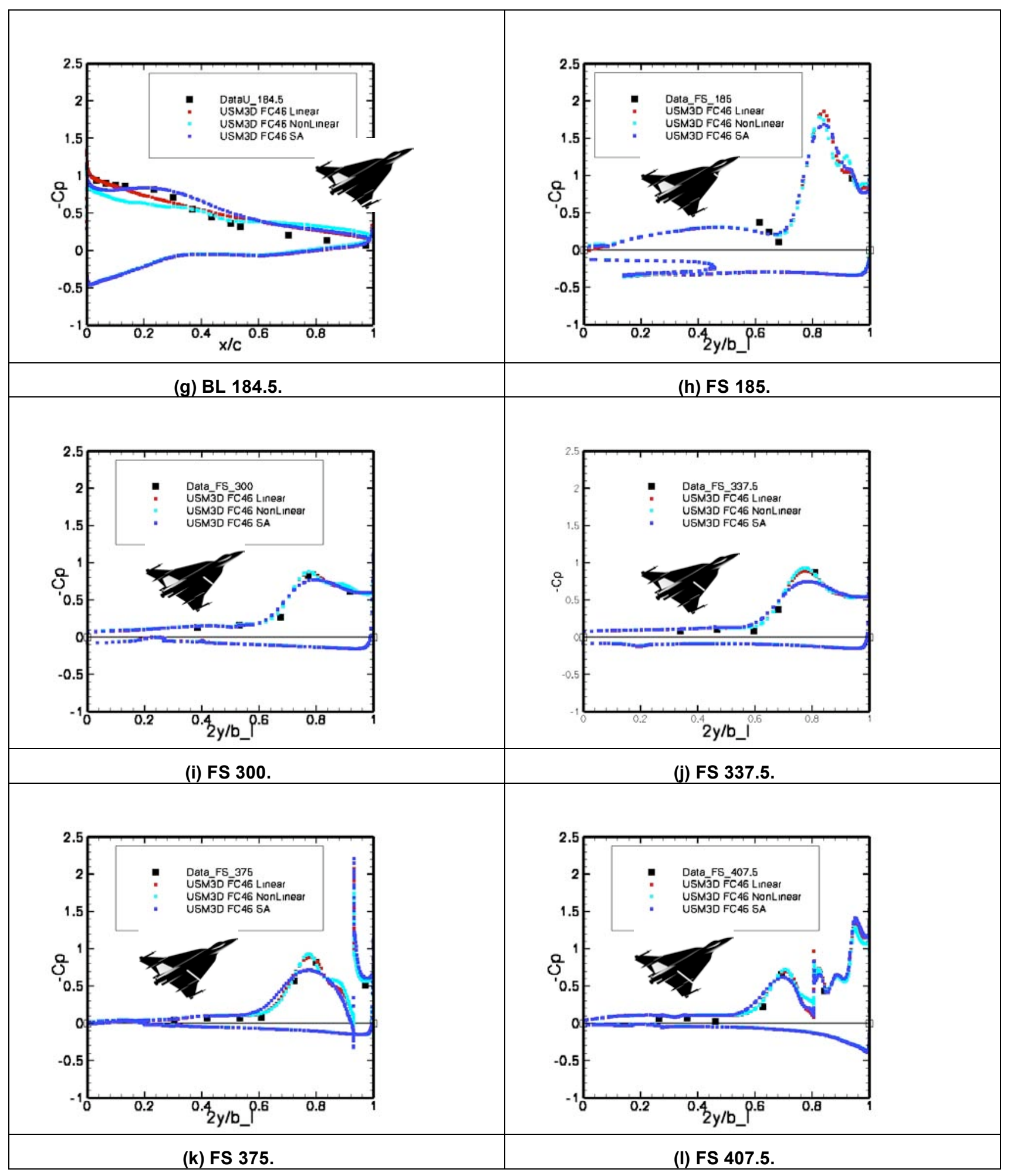

Figure 2. Continued. 


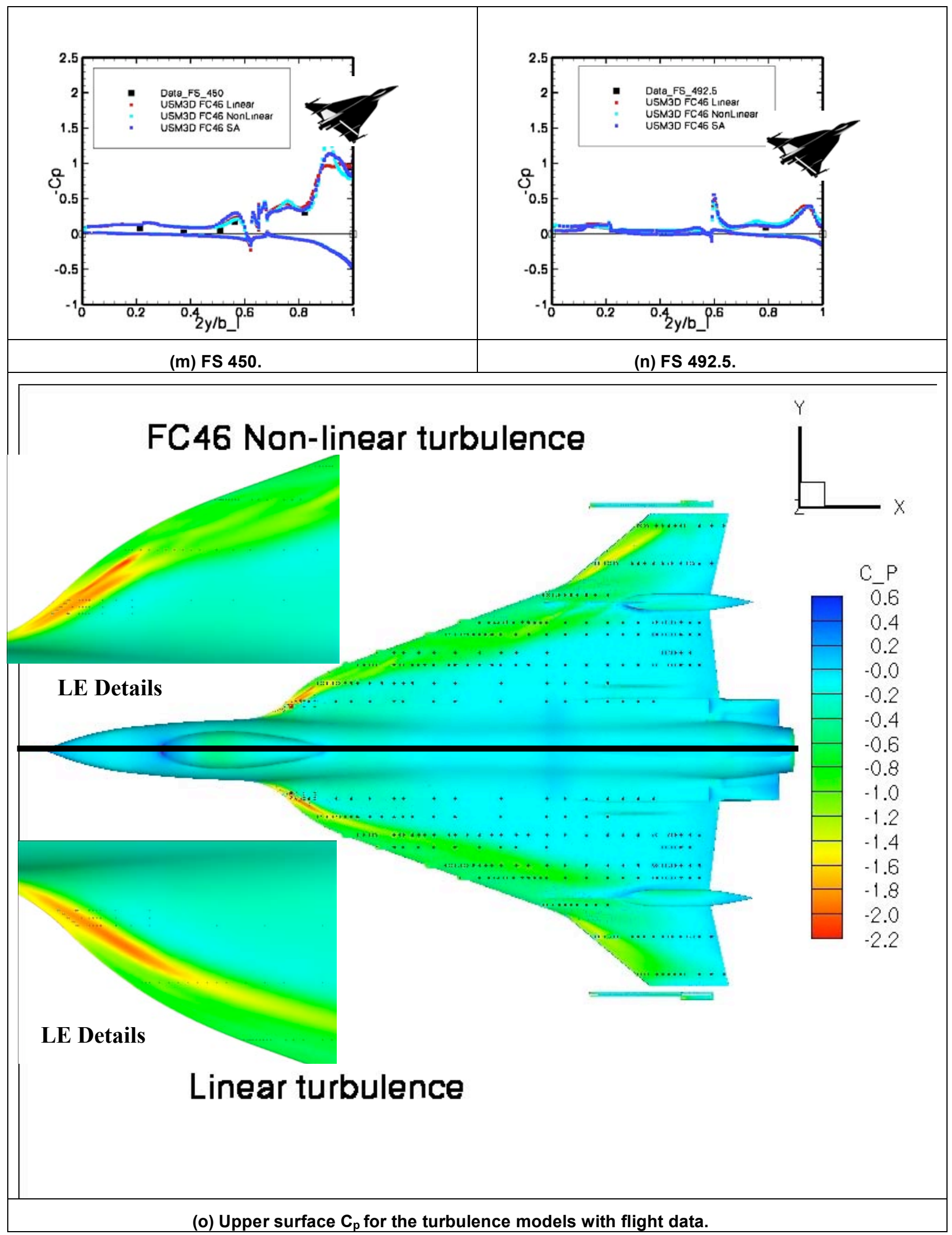

Figure 2. Concluded. 
The effects of turbulence modelling on the USM3D solutions for FC46, as determined from the various sub-parts of Fig. 2, are summarized in the following statements: (1) the two-equation non-linear k- $\varepsilon$ model is the best of the three based on comparison with the upper surface pressures, in spite of the grid not having refined viscous layers more consistent with the non-linear formulation; (2) the two-equation linear $k-\varepsilon$ model is slightly better than the SA model and almost as good as the non-linear one; and (3) all models predict well the lower surface pressures. Based on the inherent compatibility of this grid with the two-equation linear k- $\varepsilon$ model, it was selected for use with those FCs that have vortical flow; though the non-linear model performed surprisingly well, as noted Figs. 2(b)-2(c), where it predicted the suction peaks and the trailing compression better.

The black dots in Fig. 2(o) are the port locations - measurements were only made on the right wing - and the color of the circle around the dot has the same color graduation as for the USM3D surface pressures. Hence, if the colored circle is not visible then there is good agreement between the predicted and measured data at that location, which is the situation shown here. The inset figures are provided to highlight the inboard LE region where there are many ports with much agreement, as emphasized by only the black dots being visible. (See similar inset comparison figures for FC46 in Ref. 4 for flight data and CFL3D:BL-DS.) 
B. $\quad \mathrm{FC70}\left(\mathrm{M}_{\infty}=0.97, \alpha=4.37^{\circ}, \mathrm{R}_{\mathrm{n}}=88.77 \times 10^{6}\right)\left[\right.$ Flight at $\beta<1^{\circ}$, $\operatorname{modeled}$ as $\beta=0^{\circ}$ ]

The effect of the three turbulence models on the USM3D solutions for this transonic flight condition (FC70) is shown in Fig. 3 in a $\mathrm{C}_{\mathrm{p}}$ comparison with measured data and results obtained a number of years ago with CFL3D:BL-DS ${ }^{4}$ with an order of magnitude fewer cells.

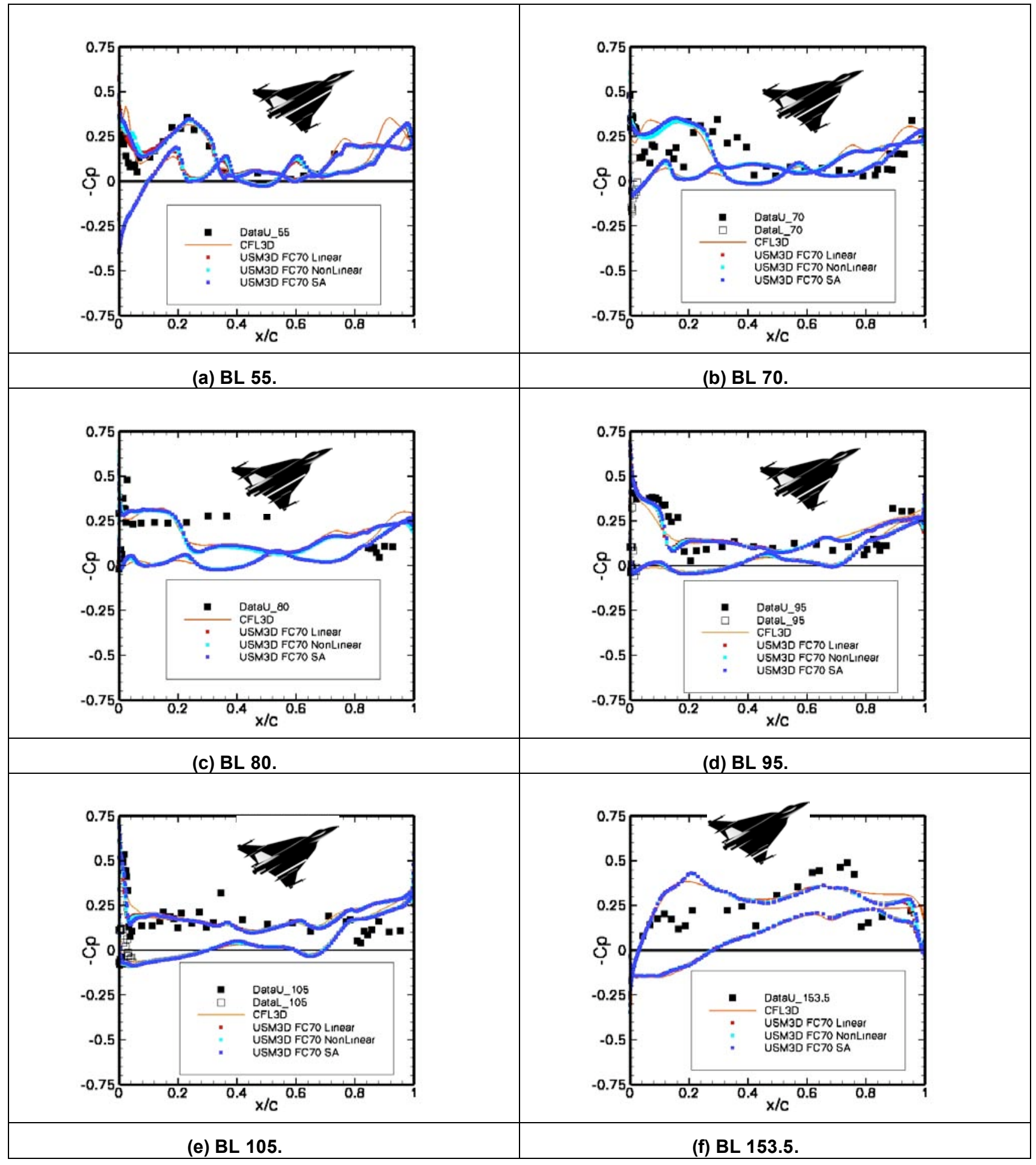

Figure 3. Effect of turbulence model on $C_{p}$ from USM3D at FC70 $\left(M_{\infty}=0.97, \alpha=4.37^{\circ}, R_{n}=88.77 \times 10^{6}\right)$; Data and CFL3D:BL-DS results from Ref. 4. 


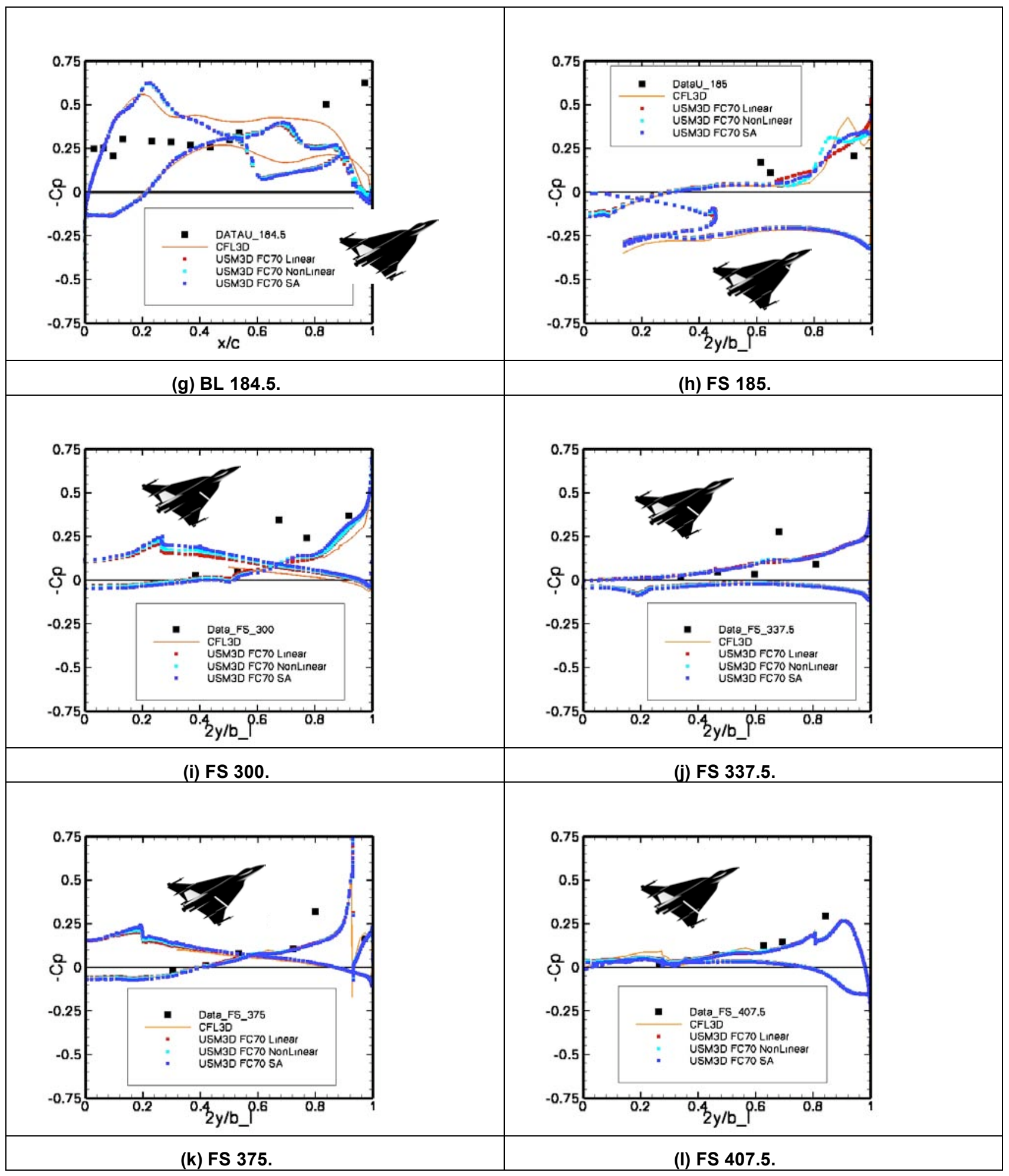

Figure 3. Continued. 


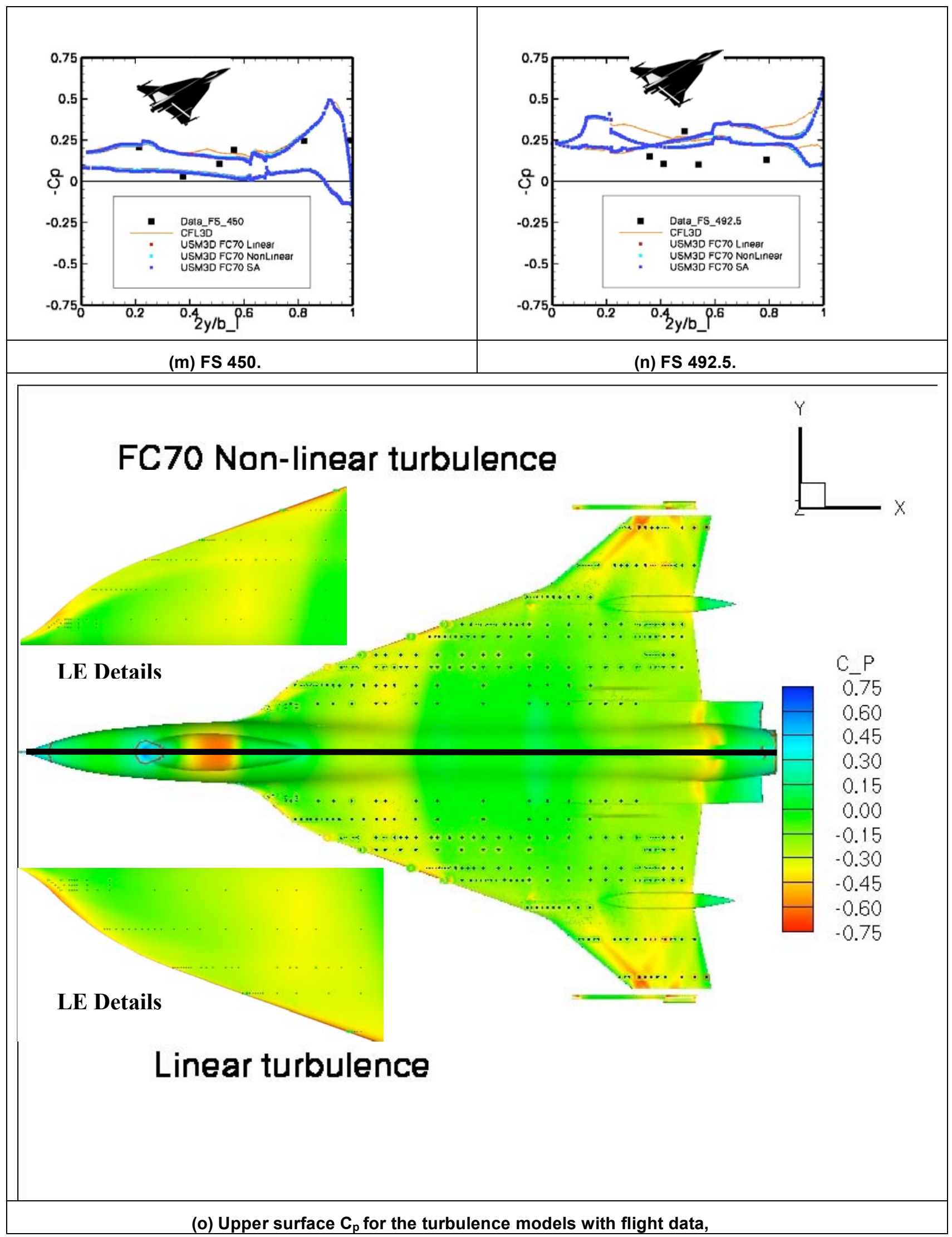

Figure 3. Concluded. 
A summary of the turbulence model study for FC70 (Figs. 3(a)-3(n)) is that there is very little effect of the model, except at FS185, on the $\mathrm{C}_{\mathrm{p}}$ results and the agreement with measured data is mixed. In general, the USM3D predictions agree better with measured data than those from CFL3D:BL-DS ${ }^{4}$, but both solutions only fairly

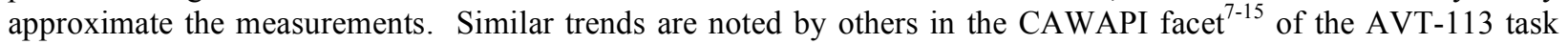
group. Moreover, from Fig. 3(a)-3(n) the predictions of USM3D are seen to agree better with data on the inner wing than on the outer. There was a hope in the CAWAPI facet that other solvers with more grid cells and other turbulence models would produce better results than those published, in spite of two geometrical issues: unmodeled, upward-deflected leading edge (LE) flap $\left(5^{\circ} \text { to } \sim 9^{\circ}\right)^{4}$ on the outer wing panel and any attendant aeroelastic effects in 1-g flight. This hope was not realized. Nevertheless, some improvements, in terms of generating the best USM3D solution possible for FC70 within the unmodeled constraints, would be expected with a new grid in which the boundary layer was refined consistent with the $\mathrm{R}_{\mathrm{n}}$ for this transonic $\mathrm{FC}$.

The USM3D $\mathrm{C}_{\mathrm{p}}$ predictions differ only slightly from those of the structured grid solver CFL3D:BL-DS ${ }^{4}-$ solution obtained on an order of magnitude fewer cells more than 5 years ago, and with the same unmodeled constraints - and have the most differences over the aft part of the wing and at FS492.5. The differences noted are not necessarily in the direction of improved data agreement.

Lastly, Fig. 3(o) does help to highlight the differences across the surface between the measured and predicted $\mathrm{C}_{\mathrm{p}}$ results, especially at some locations along the LE. The inset figures of the inboard LE regions show the location of the ports for which there is agreement or disagreement between the predicted and measured data. As before, if the color of the circle surrounding the black dot (pressure port location) and representing the measured pressure value blends into that of the USM3D background color, the agreement is good; otherwise not. (See similar inset comparison figures for FC70 in Ref. 4 for flight data and CFL3D:BL-DS.)

\section{Other subsonic comparisons}

Now that the linear turbulence model has been chosen for use with the USM3D solver with this base unstructured grid, solutions are obtained with this combination at both symmetrical, $\beta=\sim 0^{\circ},(\mathrm{FC} 7, \mathrm{FC} 19, \mathrm{FC} 25)$ and asymmetrical, $\beta \pm \sim 5^{\circ}$, (FC50, FC51) flight conditions. Some of these are shown and all are discussed using the following figures. Solutions for FC7 and FC19 were primarily obtained in order to compare with the boundary layer (B.L.) rake data ${ }^{4}$ and skin-friction data ${ }^{4}$, respectively.

A. Symmetric: FC25 $\left(M_{\infty}=0.242, \alpha=19.84^{\circ}, R_{n}=32.22 \times 10^{6}\right)\left[\right.$ Flight at $\beta<1^{\circ}$, modeled as $\left.\beta=0^{\circ}\right]$

Figure 4 for FC25 also has comparisons with the previous computational results ${ }^{4}$. 


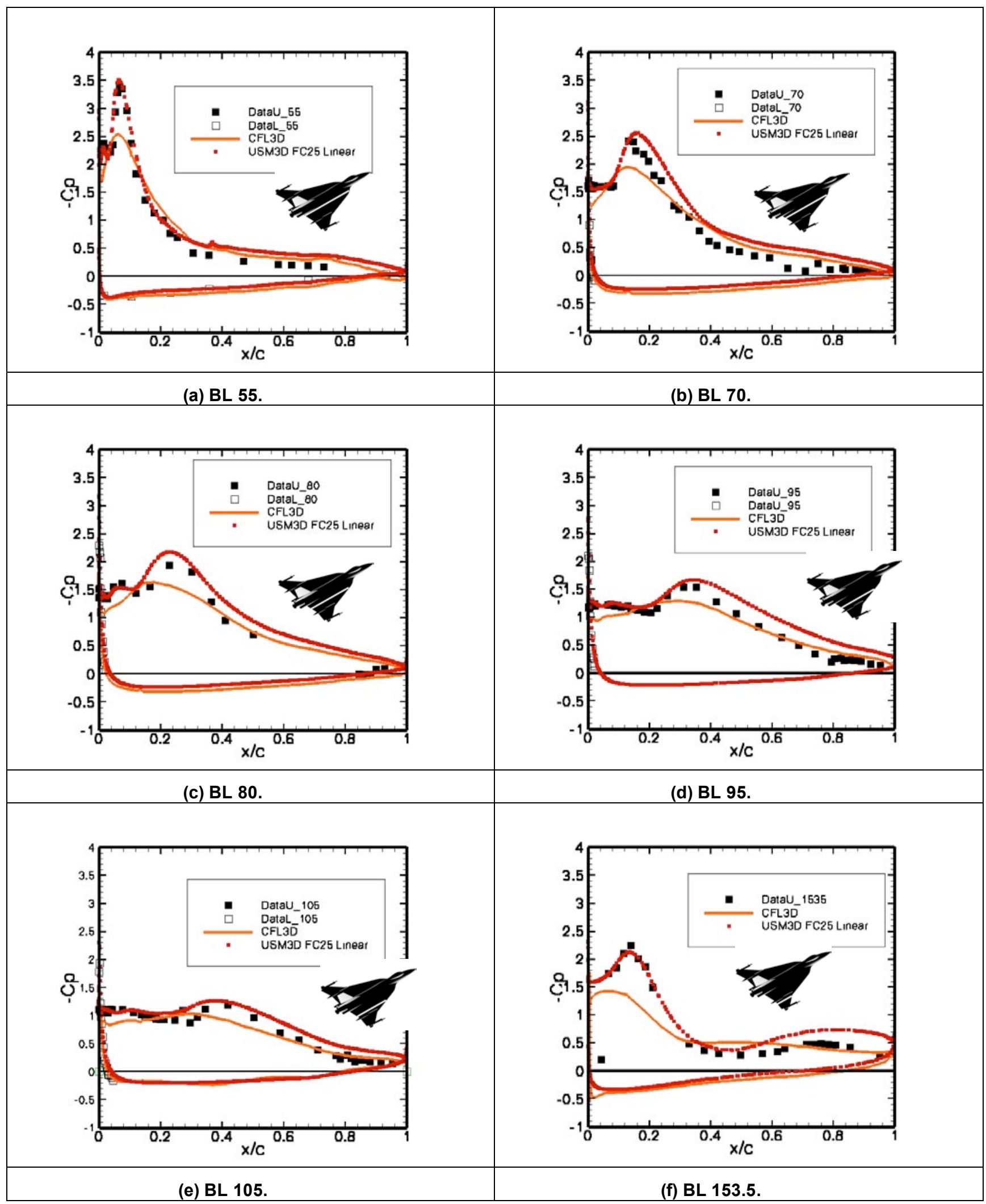

Figure 4. Prediction of $C_{p}$ flight data from USM3D at FC25 $\left(M_{\infty}=0.242, \alpha=19.84^{\circ}, R_{n}=32.22 \times 10^{6}\right)$; Data and CFL3D:BL-DS results from Ref. 4. 




Figure 4. Continued.

14

American Institute of Aeronautics and Astronautics 


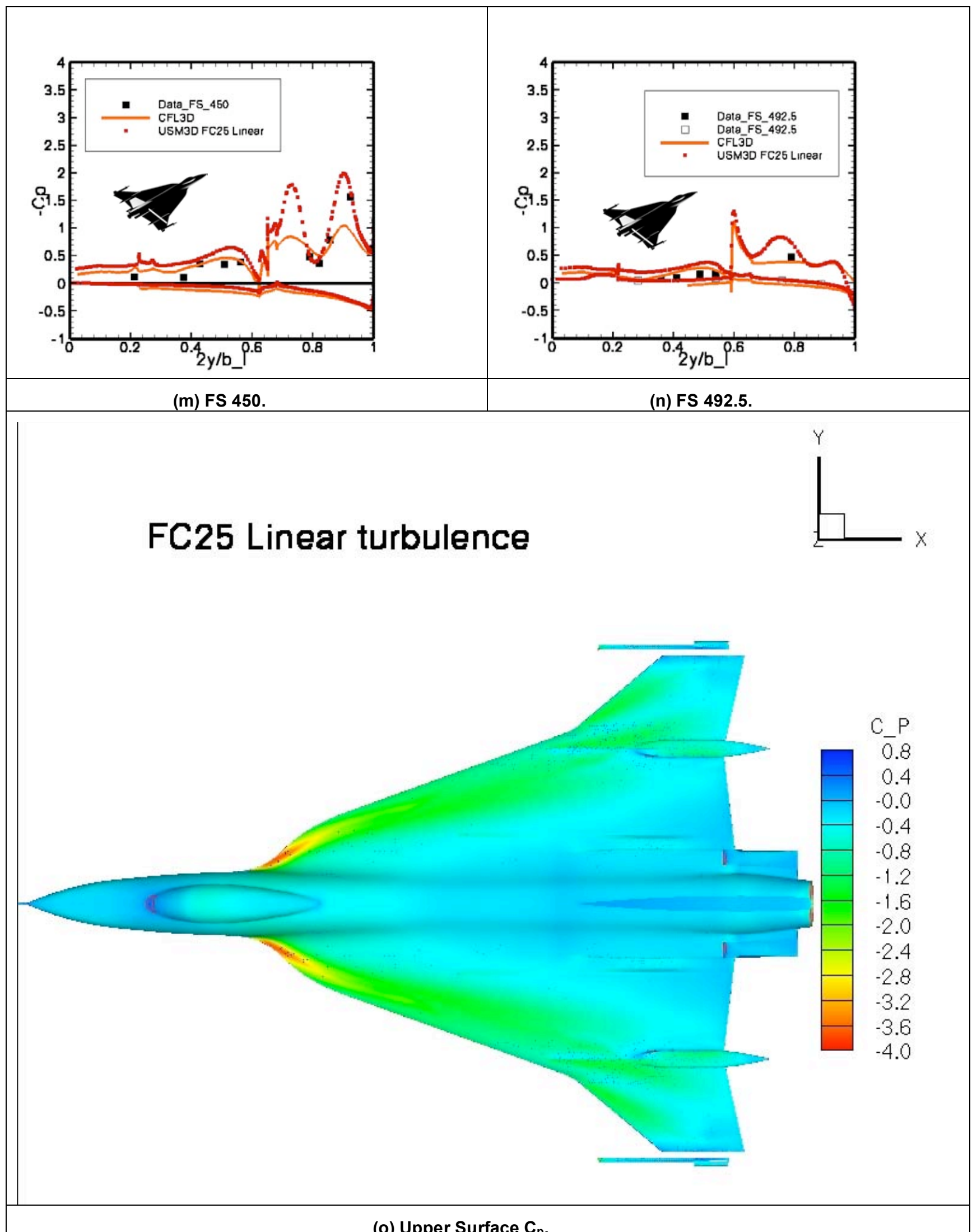

(o) Upper Surface $C_{p}$.

Figure 4. Concluded. 
For FC25, the USM3D solution is in quite good agreement with measured data and offers some significant improvement over published CFL3D $\mathrm{C}_{\mathrm{p}}$ results ${ }^{4}$ - solution obtained on an order of magnitude fewer cells more than 5 years ago. An adaptive grid may offer additional improvement, but the results shown are remarkable, in that they predict all the suction peaks well and capture the overall surface $\mathrm{C}_{\mathrm{p}}$ chordwise and spanwise distributions.

\section{B. Asymmetric [Flight parameter value for $\beta \neq 0^{\circ}$, modeled]}

As seen in Figs. 5 and 6, the USM3D solver generally predicts well the measured data for these two asymmetric flows at all BLs and FSs, including the peak values at BL55 but misses the ones at BL153.5. This solver also captures the FS185 measured data well. In general, the predictions at FC51 $\left(\beta=-4.58^{\circ}\right)$ are slightly better than those at FC50 $\left(\beta=+5.31^{\circ}\right)$. In particular, for FC51 at BL153.5 the measured $\mathrm{C}_{\mathrm{p}}$ data aft of the peak is even well predicted, though the peak value is not. The situations where the peak is missed may be improved by using the non-linear turbulence model, as noted for FC46, or using an adaptive grid with the linear model. 
i. $\operatorname{FC50}\left(M_{\infty}=0.434, \alpha=13.56^{\circ}, \beta=+5.31^{\circ}, R_{n}=39.41 \times 10^{6}\right)$

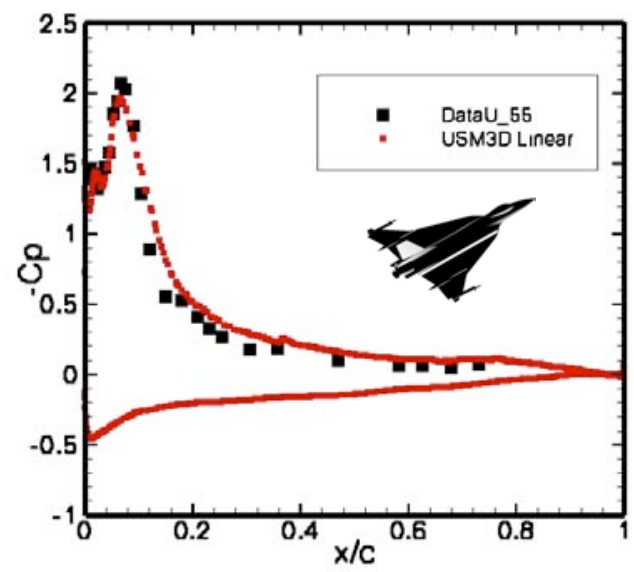

(a) BL 55.

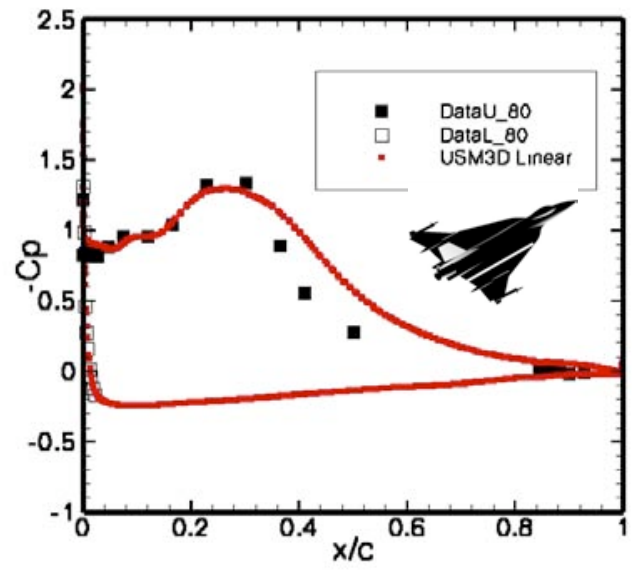

(c) BL 80 .



(e) BL 105.

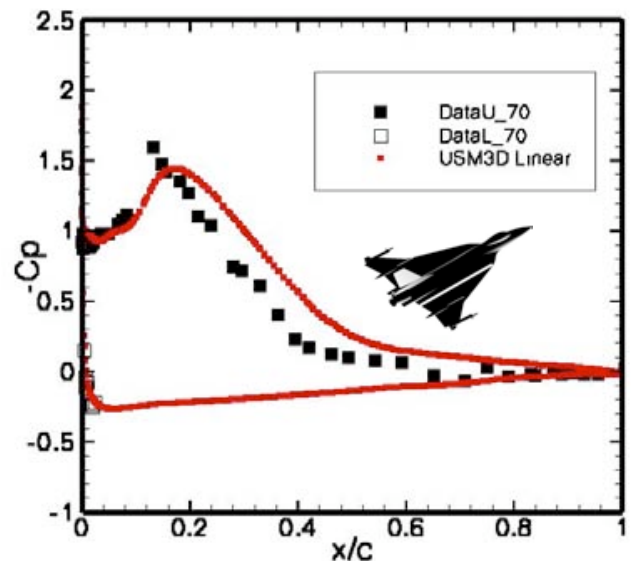

(b) BL 70.

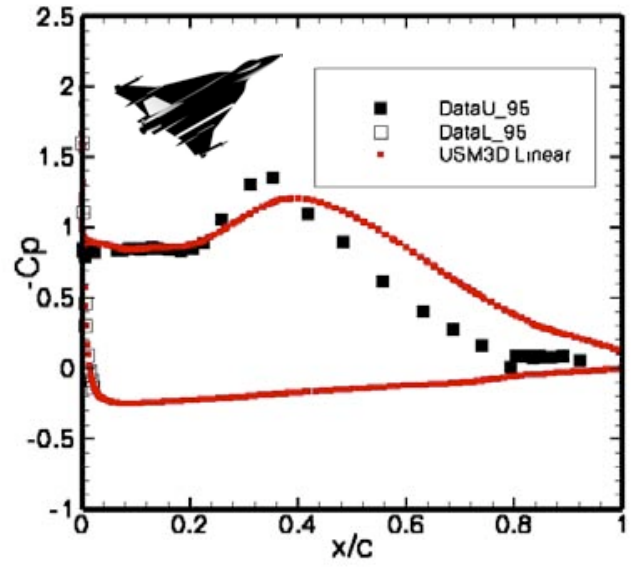

(d) BL 95.

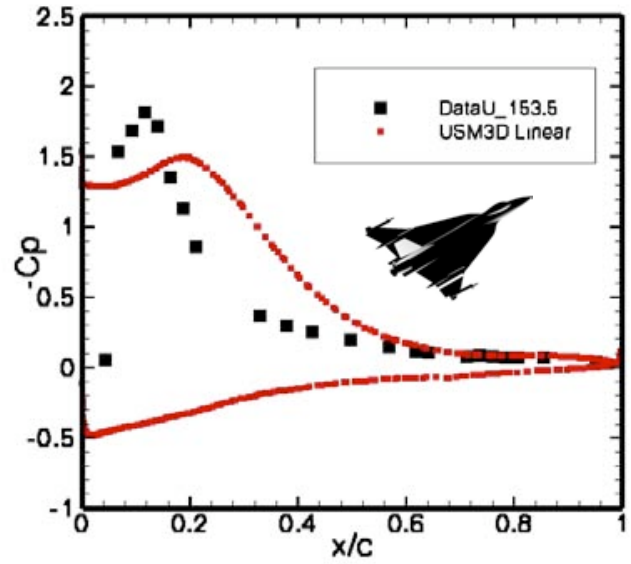

(f) BL 153.5.

Figure 5. Predicted and measured $C_{p}$ data at FC50 $\left(M_{\infty}=0.434, \alpha=13.56^{\circ}, \beta=+5.31^{\circ}, R_{n}=39.41 X 10^{6}\right)$; Data from internet citation in Ref. 4. 


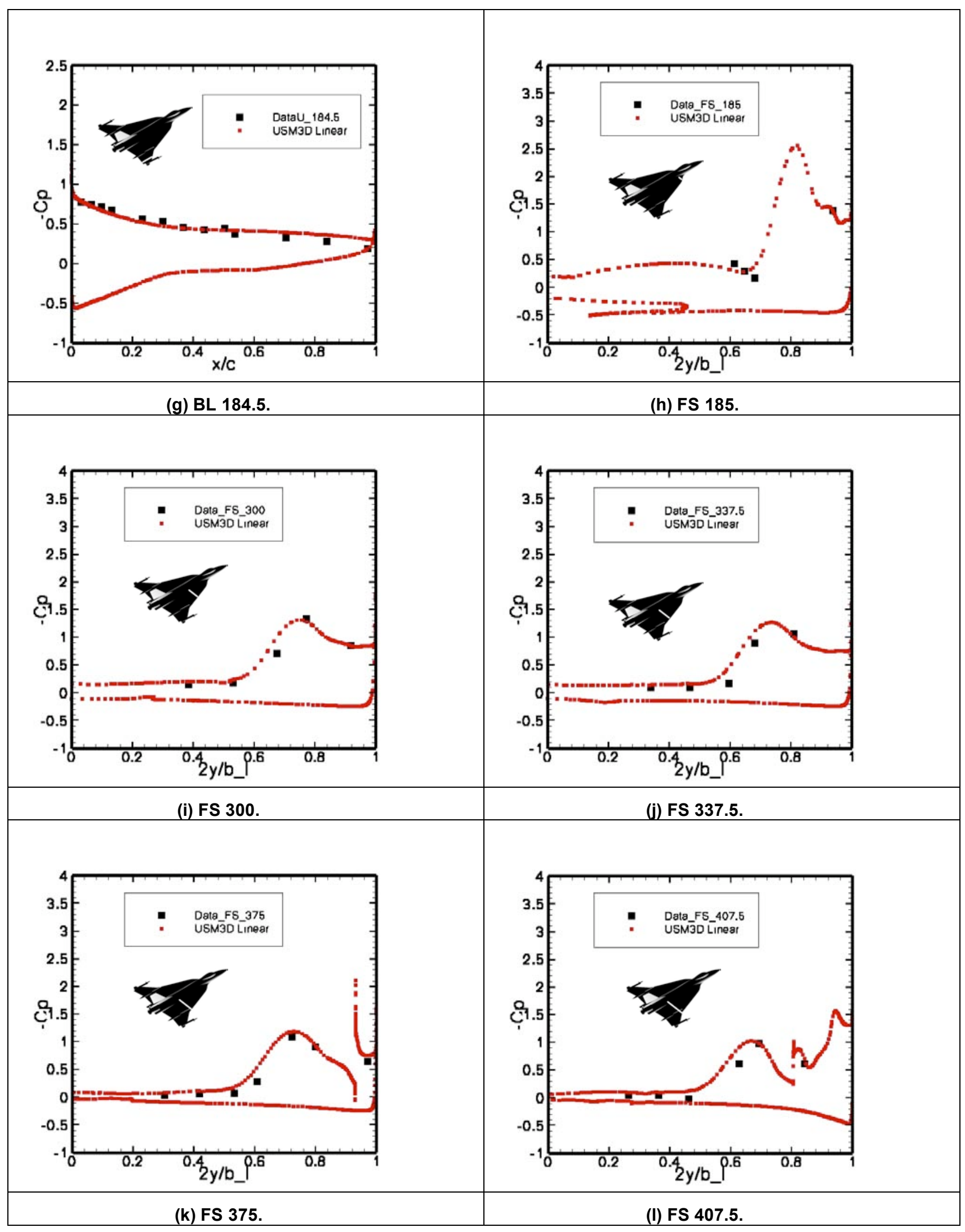

Figure 5. Continued. 


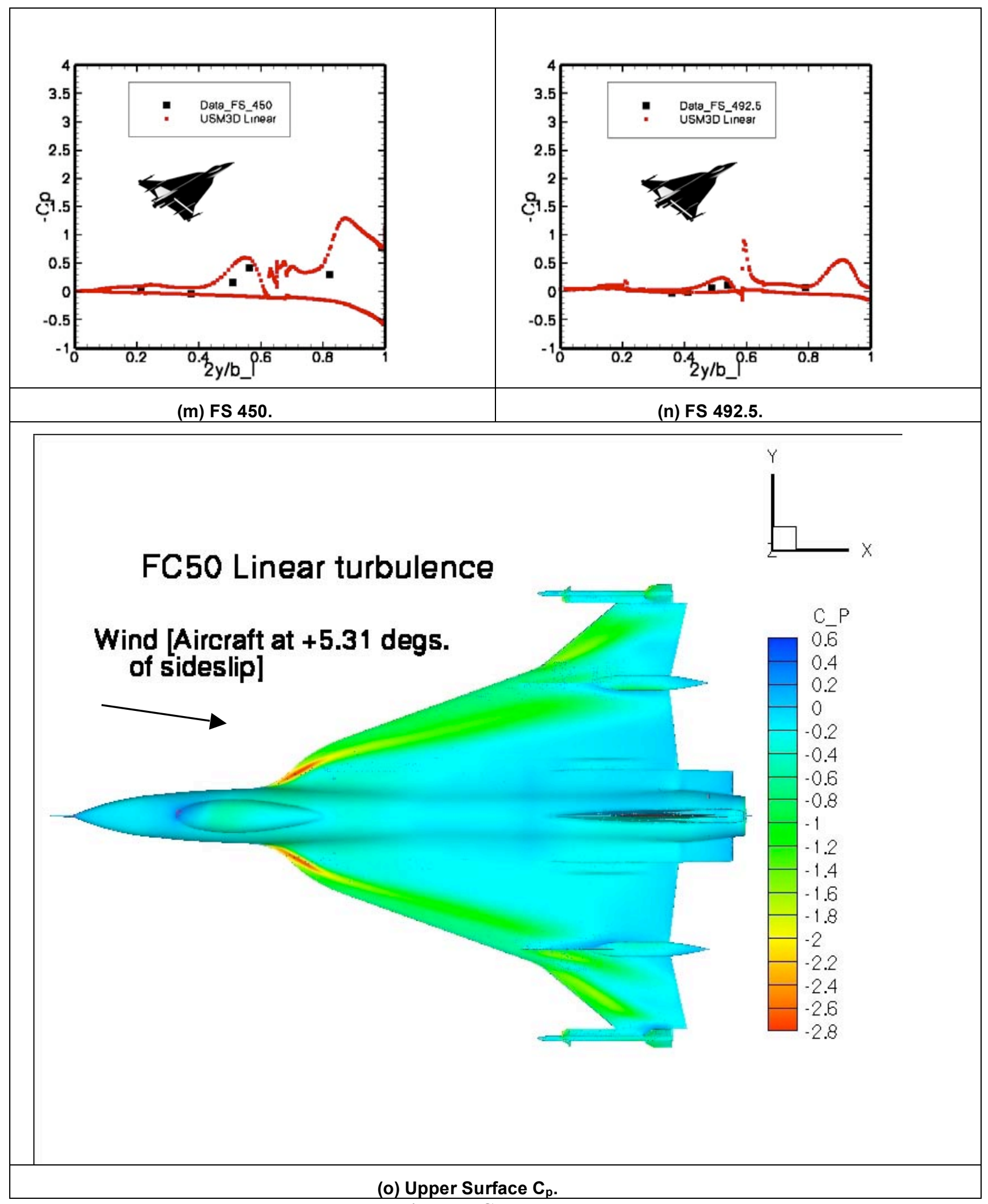

Figure 5. Concluded. 
ii. $\operatorname{FC51}\left(\mathrm{M}_{\infty}=0.441, \alpha=12.89^{\circ}, \beta=-4.58^{\circ}, R_{n}=38.95 \times 10^{6}\right)$

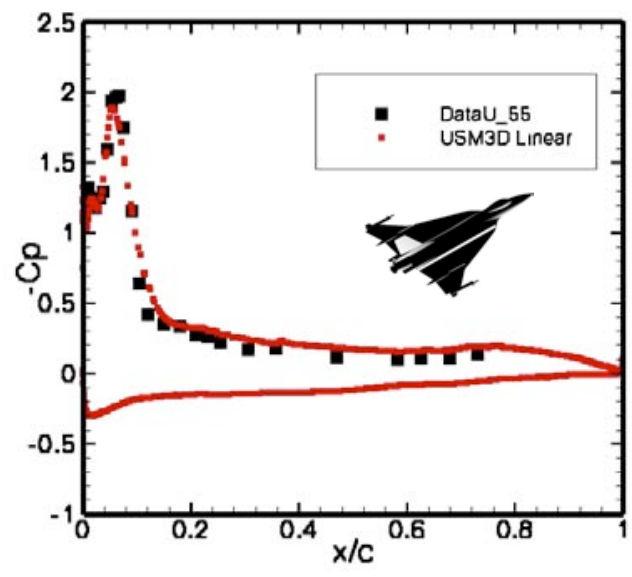

(a) BL 55.

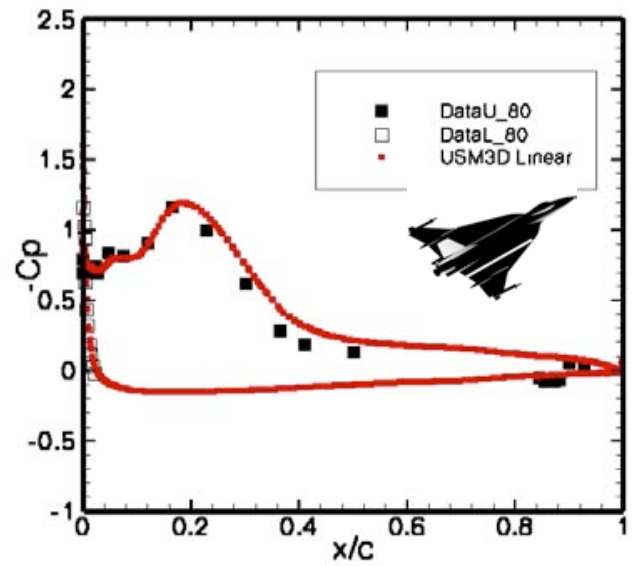

(c) BL 80 .

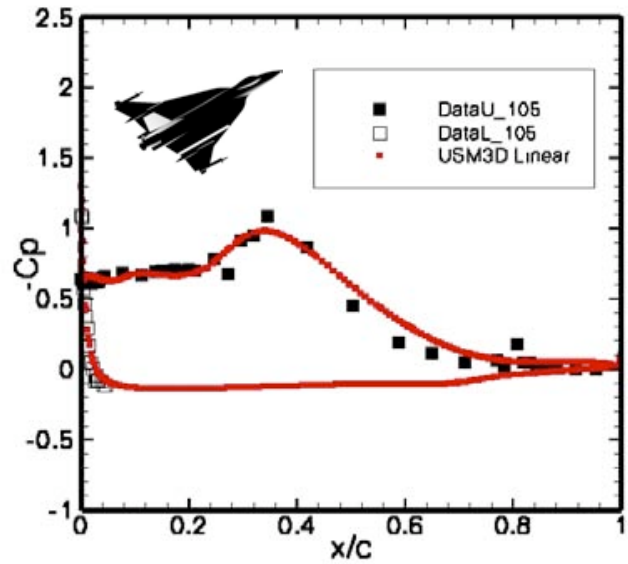

(e) BL 105.

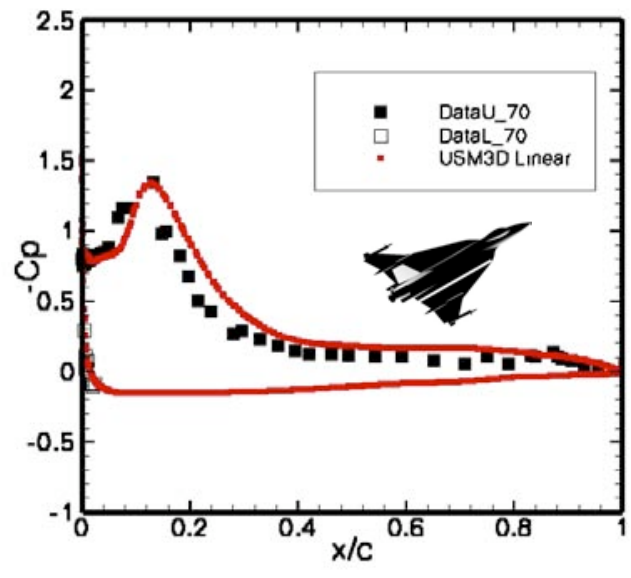

(b) BL 70.



(d) BL 95.

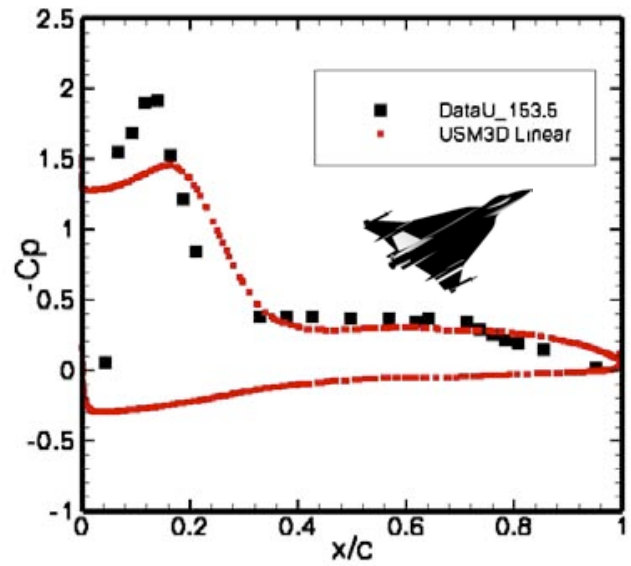

(f) $\mathrm{BL}$ 153.5.

Figure 6. Predicted and measured $C_{p}$ data at FC51 $\left(M_{\infty}=0.441, \alpha=12.89^{\circ}, \beta=-4.58^{\circ}, R_{n}=38.95 X 10^{6}\right)$; Data from internet citation in Ref. 4. 


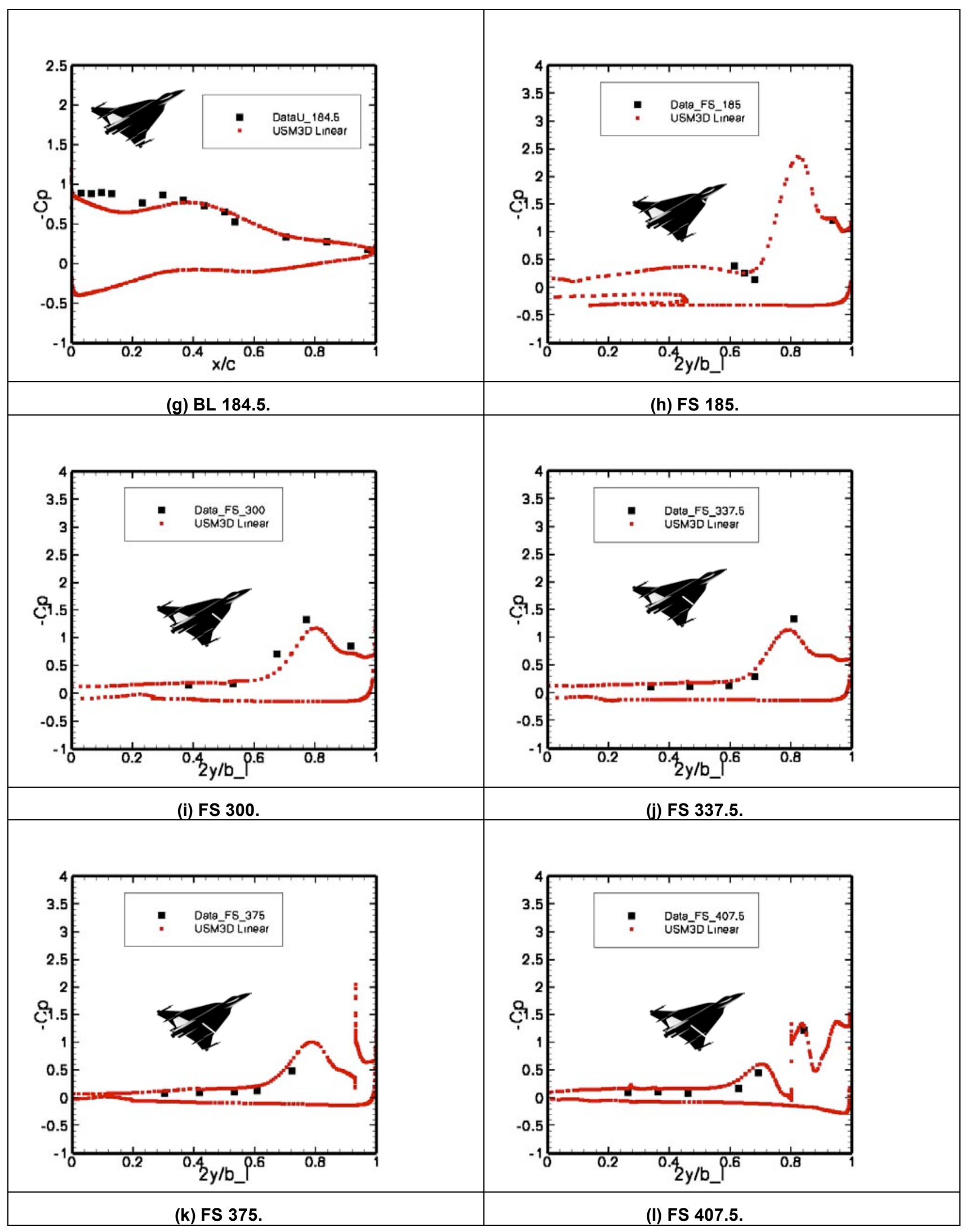

Figure 6. Continued. 


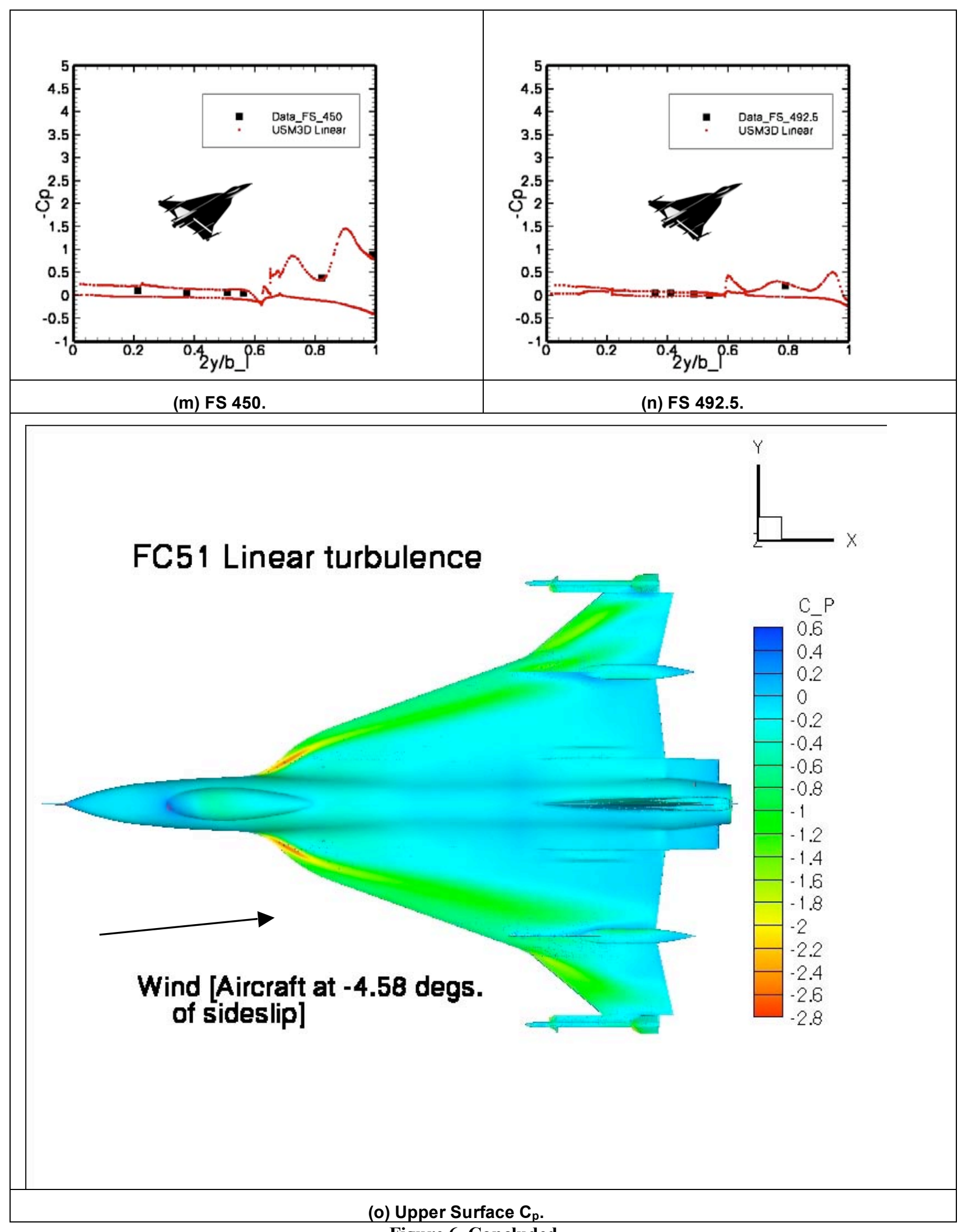

Figure 6. Concluded. 


\section{Boundary layer}

Figure 7 presents comparisons of predicted and measured boundary layer profiles at FC7. These profiles are defined as the ratio of velocity magnitude in the boundary layer to that at the rake-extreme total pressure tube (top-most one), located 1.8 inches off the surface and normal to it. The B.L. rake positions were chosen ${ }^{4}$ so that \#3 would be in basic free-stream flow, \#4 underneath the primary vortex, \#5 underneath the secondary vortex, and \#7 on the secondary vortex separation line. Regarding the USM3D and PAB3 $\mathrm{D}^{7}$ solutions, both predict the entire profiles well for all four B.L. rakes, though USM3D is slightly better for rakes \#3 and \#7. For rake \#7, both underestimate the profiles from 0.25 to 1.25 inches off the surface. Near the wall, both methods predict the profiles very well at all rake locations. With respect to the published results from CFL3D:BL-DS ${ }^{4}$ - solution obtained on an order of magnitude fewer cells more than 5 years ago, USM3D shows the most significant prediction improvements for Rakes \#5 and \#7 - these are near the LE. Moreover, USM3D offers slight improvement near the wall for \#3 over that of the PAB3D and CFL3D:BL-DS profiles.

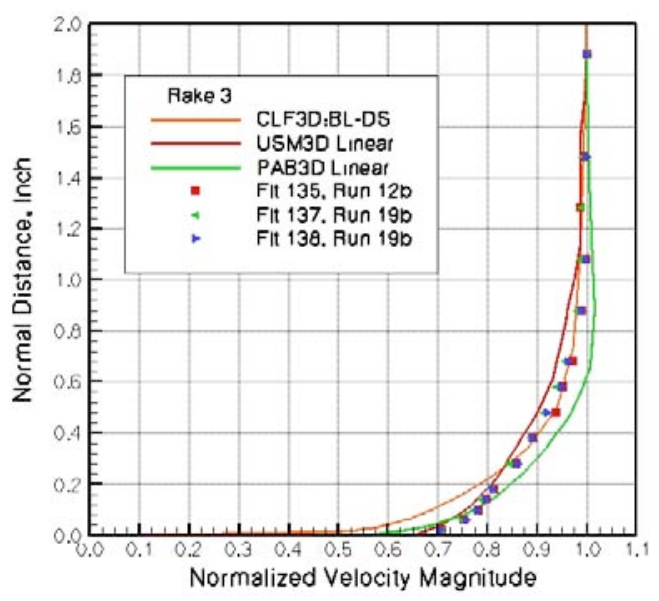

Rake 3; FS .302.17, BL -52.93.

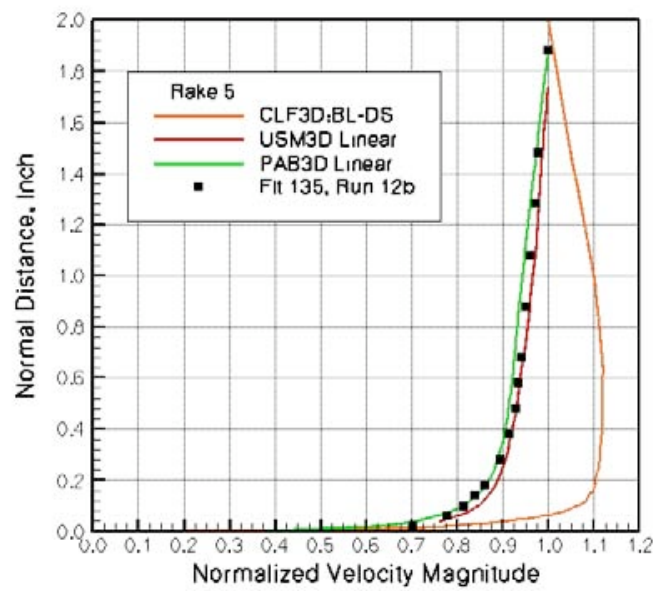

Rake 5; FS 295.52, BL -94.33.

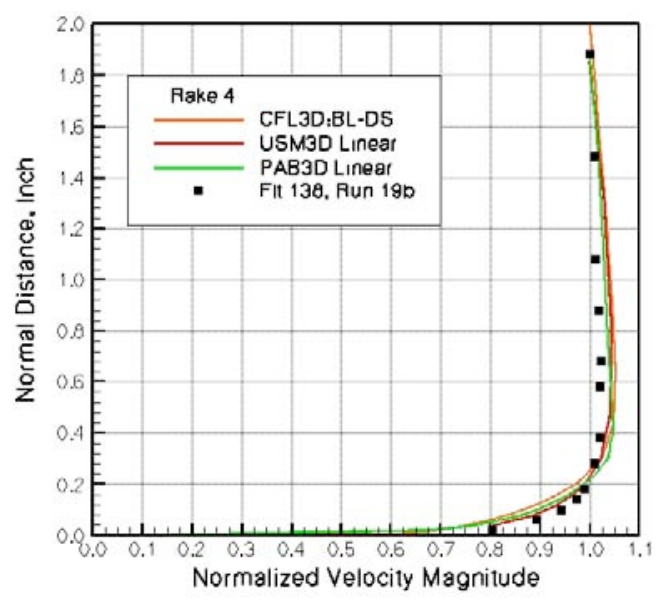

Rake 4; FS 293.45, BL -76.22.

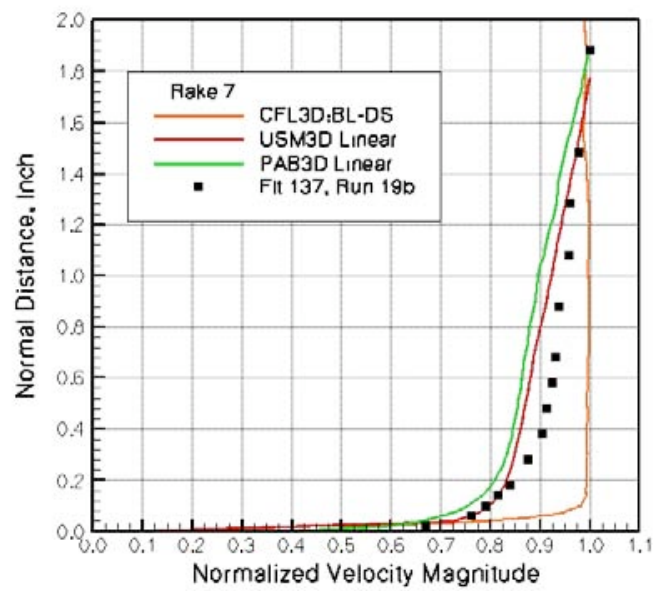

Rake 7; FS 294.59, BL -96.06.

Figure 7. Velocity profiles for boundary layer rakes on F-16XL for FC 7: $\left(M_{\infty}=0.304, \alpha=11.89^{\circ}\right.$, $R_{n}=44.4 \times 10^{6}$ ); Data and CFL3D:BL-DS from Ref. 4. 
In order to understand better this difference in boundary layer profiles near the LE for the USM3D solution, Figs. 8-9 were prepared to look at the total pressure contours at FS300 - the nominal value where the B.L. rakes are located - and at FS330 - the location where the skin friction data were measured. The purpose of these figures was to ascertain whether there was significant off-surface vortical flow activity in the vicinity of the LE, where the secondary vortex would be expected to occur. These two figures
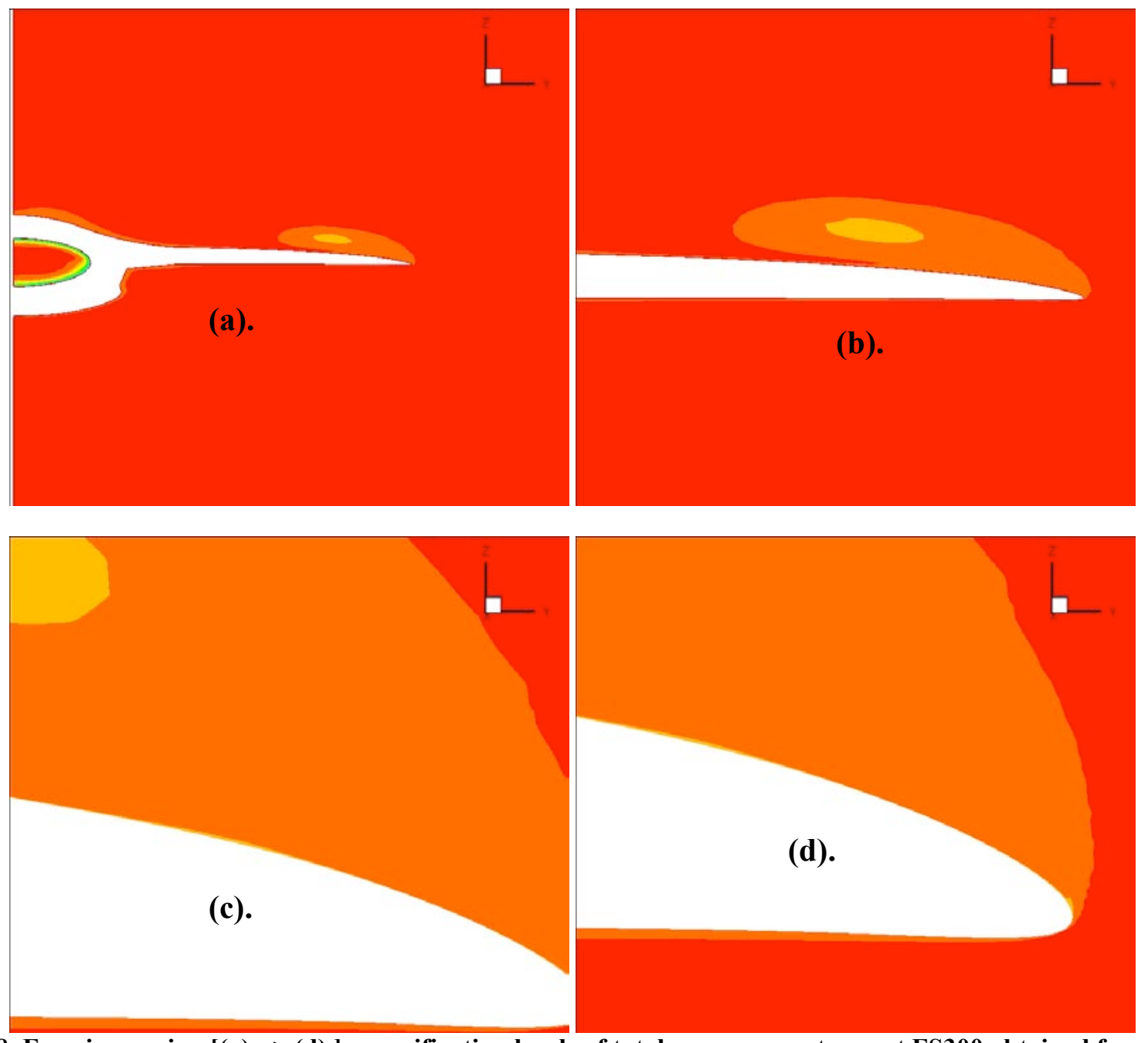

Figure 8. Four increasing [(a). -> (d).] magnification levels of total pressure contours at FS300 obtained from USM3D for FC7 $\left(M_{\infty}=0.304, \alpha=11.89^{\circ}, R_{n}=44.4 \times 10^{6}\right)$. 

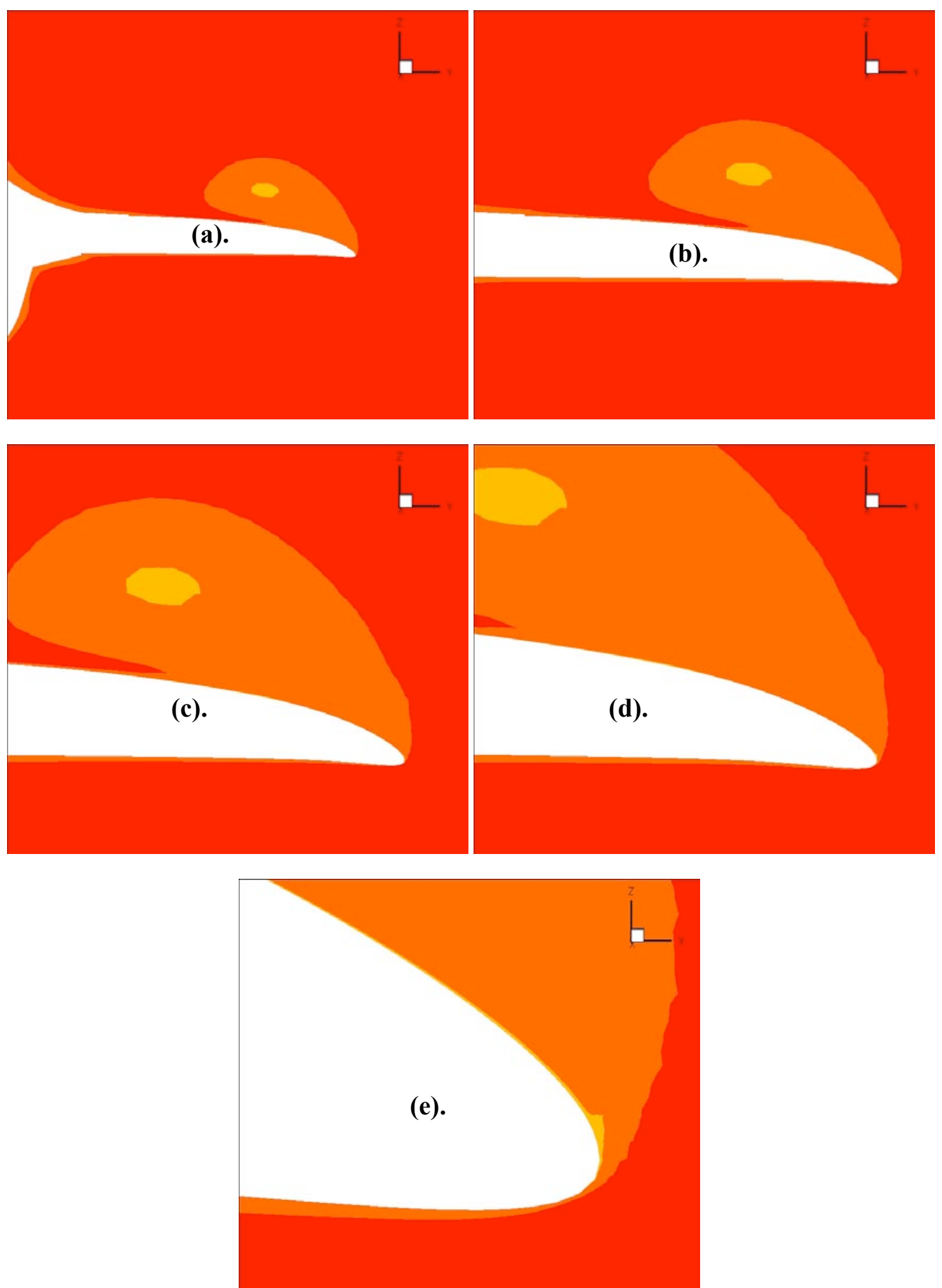

Figure 9. Five increasing [(a). - $>$ (e).] magnification levels of total pressure contours at FS330 obtained from USM3D for FC7 $\left(M_{\infty}=0.304, \alpha=11.89^{\circ}, R_{n}=44.4 \times 10^{6}\right)$.

illustrate two findings and they are that there is : (1) little change between the two flow-fields, only 30 inches apart (See Fig. 10 for relative locations - reconstructed from Ref. 4); and (2) little detailed activity is seen near the LE - 
even with increased magnification - indicating that the anticipated location of the secondary vortex is poorly captured with this grid/turbulence model combination at either FS.
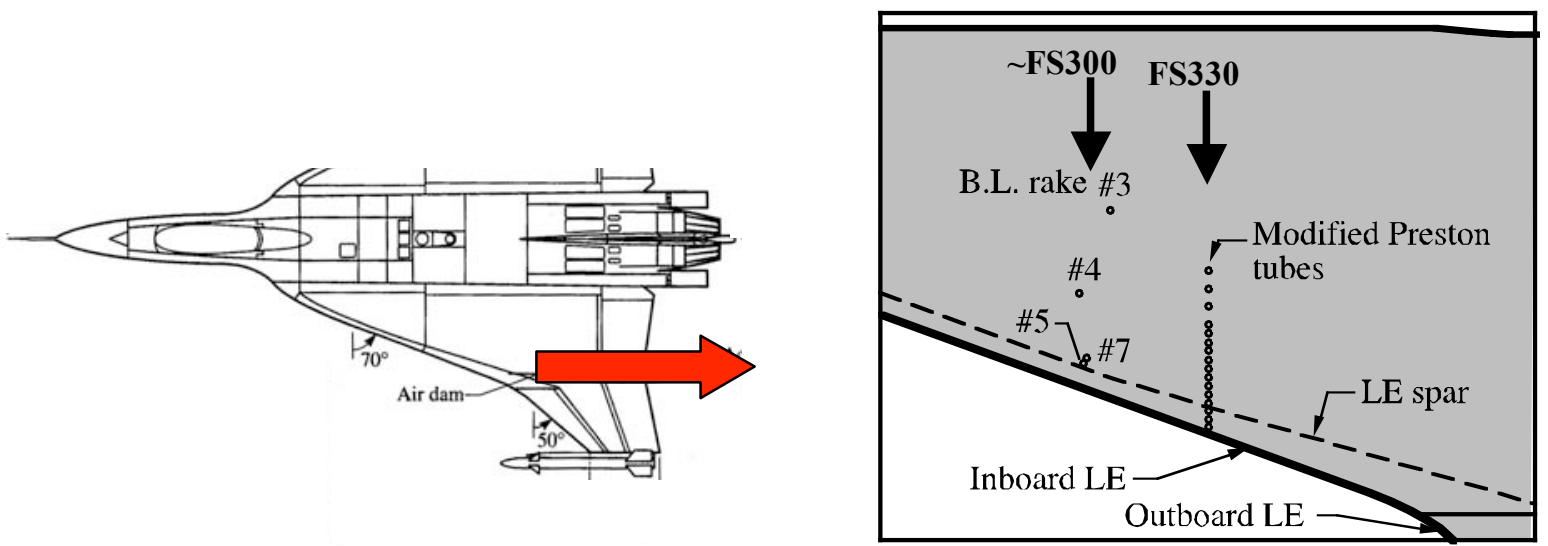

Figure 10. General arrangement of rake and modified Preston tube relative locations on F-16XL-1 left wing; pressure instruments oriented for $\alpha=13^{\circ} ; M_{\infty}=0.29$; and $R_{n}=46.1 \times 10^{6}$.

\section{Skin friction}

Figure 11 shows the $\mathrm{c}_{\mathrm{f}}$ predictions and measured data for the USM3D and PAB3 $\mathrm{D}^{7}$ solvers using the linear turbulence model and CFL3D:BL-DS ${ }^{4}$. All solvers predict well the location of the skin friction peak for the primary vortex but also have a smaller gradient on either side of the measured peak. The USM3D solution results are better than the other two in terms of being closer to the peak skin friction value and its inboard gradient. Both the PAB3D and CFL3D:BL-DS predict the secondary vortex peak value and location well and better than that of USM3D. This was to be expected based on the preceding discussion.

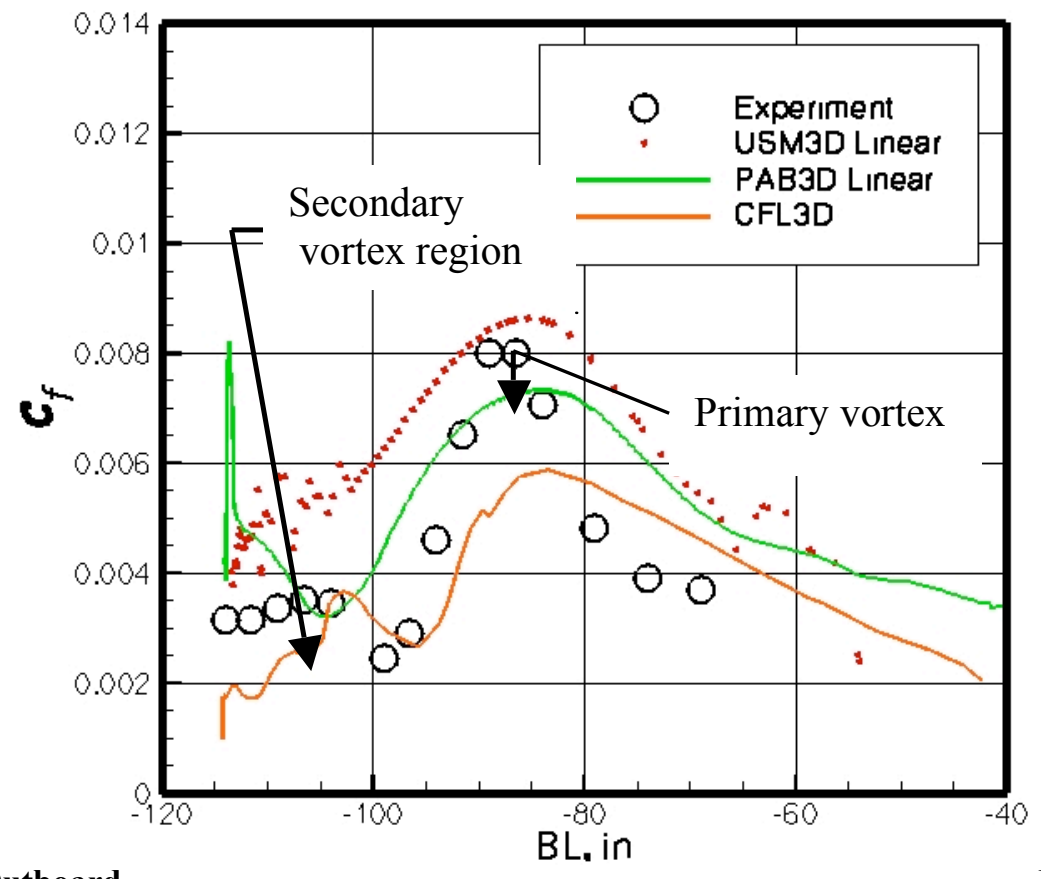

Outboard

Inboard

Figure 11. Skin friction on F-16XL-1 airplane at FS 330 for FC 19: $\left(M_{\infty}=0.36, \alpha=11.85^{\circ}, R_{n}=46.8 \times 10^{6}\right)$; Data and CFL3D:BL-DS from Ref. 4. 


\section{Conclusions}

Based on the studies and comparisons presented in this paper for the USM3D solver, the following conclusions are reached:

A. The common grid used for all USM3D solutions presented yields converged results for each of the various turbulent models employed; namely, the two-equation linear and non-linear k- $\varepsilon$ models and the SA. One pleasant surprise was that the non-linear version worked very well on this grid and the linear version worked almost as well in terms of $\mathrm{C}_{\mathrm{p}}$ predictions for vortex dominated flows.

B. The two-equation linear and non-linear $\mathrm{k}-\varepsilon$ models were better than the SA turbulence model in predicting the measured $C_{p}$ data for vortex dominated flows. Some further improvement may be expected for these flows if an adaptive grid is used at the higher angles-of-attack, but the results to date have been very encouraging in this first test of the new code version on a complex airplane.

C. The transonic predictions with either the two-equation linear or non-linear k- $\varepsilon$ model show no appreciable improvement in terms of $\mathrm{C}_{\mathrm{p}}$ predictions over those from the $\mathrm{SA}$ model or published results from the structured grid solver CFL3D:BL-DS - solution obtained on an order of magnitude fewer cells more than 5 years ago. This is one place where a finer grid in the boundary layer will likely prove to be beneficial. Further benefits could be expected by accounting for the unmodeled, upward deflection of the outboard leading-edge flap at this flight condition and any attendant aeroelastic effects in 1-g flight.

D. Using the two-equation linear $k-\varepsilon$ model produced the following results: (1) There was some improvement in the $\mathrm{C}_{\mathrm{p}}$ predictions for two vortical flow flight conditions, FC25 and FC46, relative to published results from the structured grid solver CFL3D:BL-DS - solution obtained on an order of magnitude fewer cells more than 5 years ago; (2) The effects of sideslip are well predicted, though there is some room for improvement; (3) The boundary layer profiles are generally well predicted, especially near the wall, compare favorably with the results from PAB3D - a structured solver with the same turbulence model - and are overall better than the CFL3D:BL-DS predictions; and (4) The primary vortex skin friction peak value and location are well predicted, but its nearby gradients and the secondary vortex features are not. These results differ from both those of PAB3D and CFL3D:BL-DS.

E. A summary of the preceding is that the USM3D solver can be used in an engineering environment to predict flow physics on a complex configuration at flight Reynolds numbers with a two-equation linear $k-\varepsilon$ turbulence model. 
Appendix
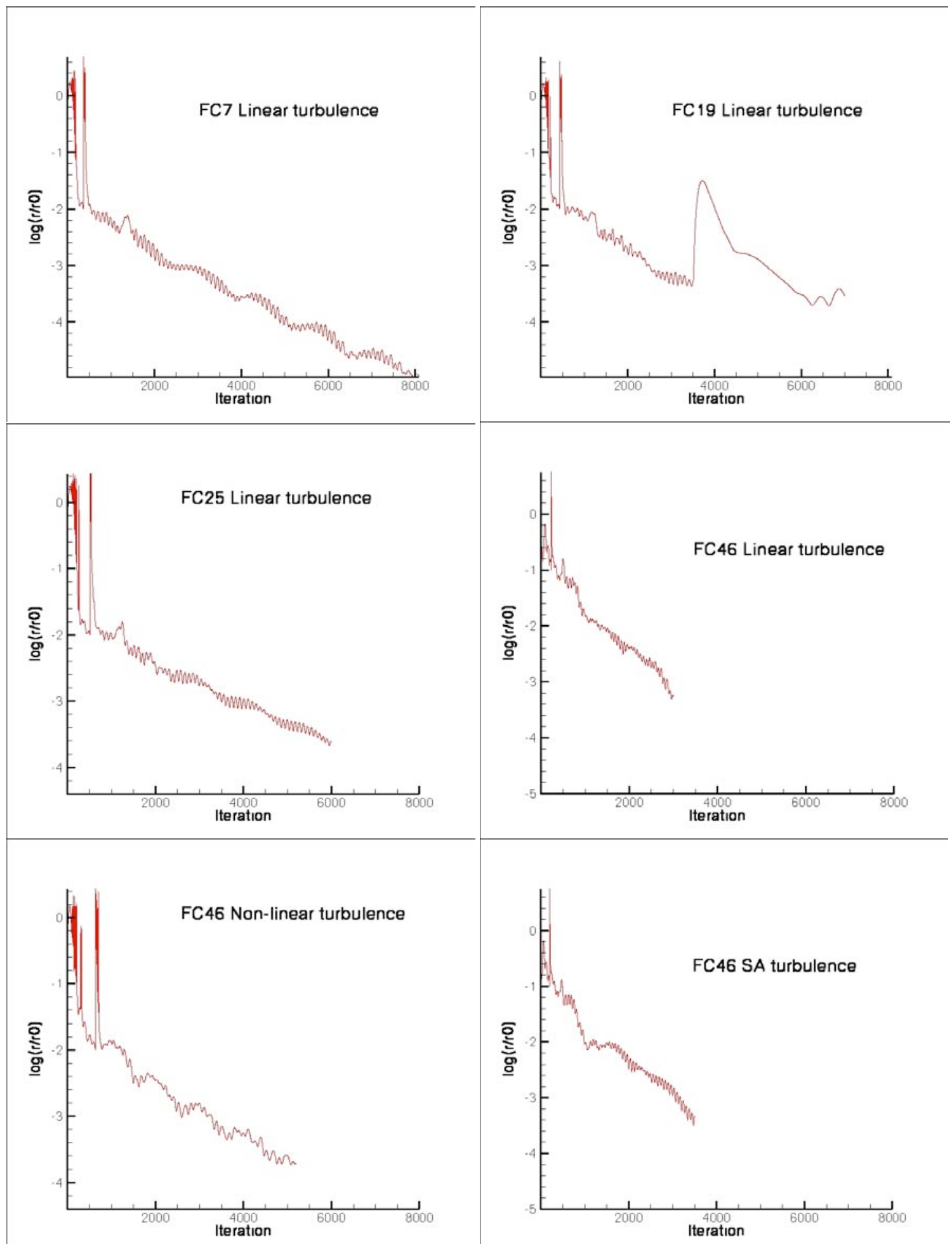

Figure A1. Convergence histories of USM3D solutions for FC7, FC19, FC25, FC46, FC50, FC51 and FC70. 


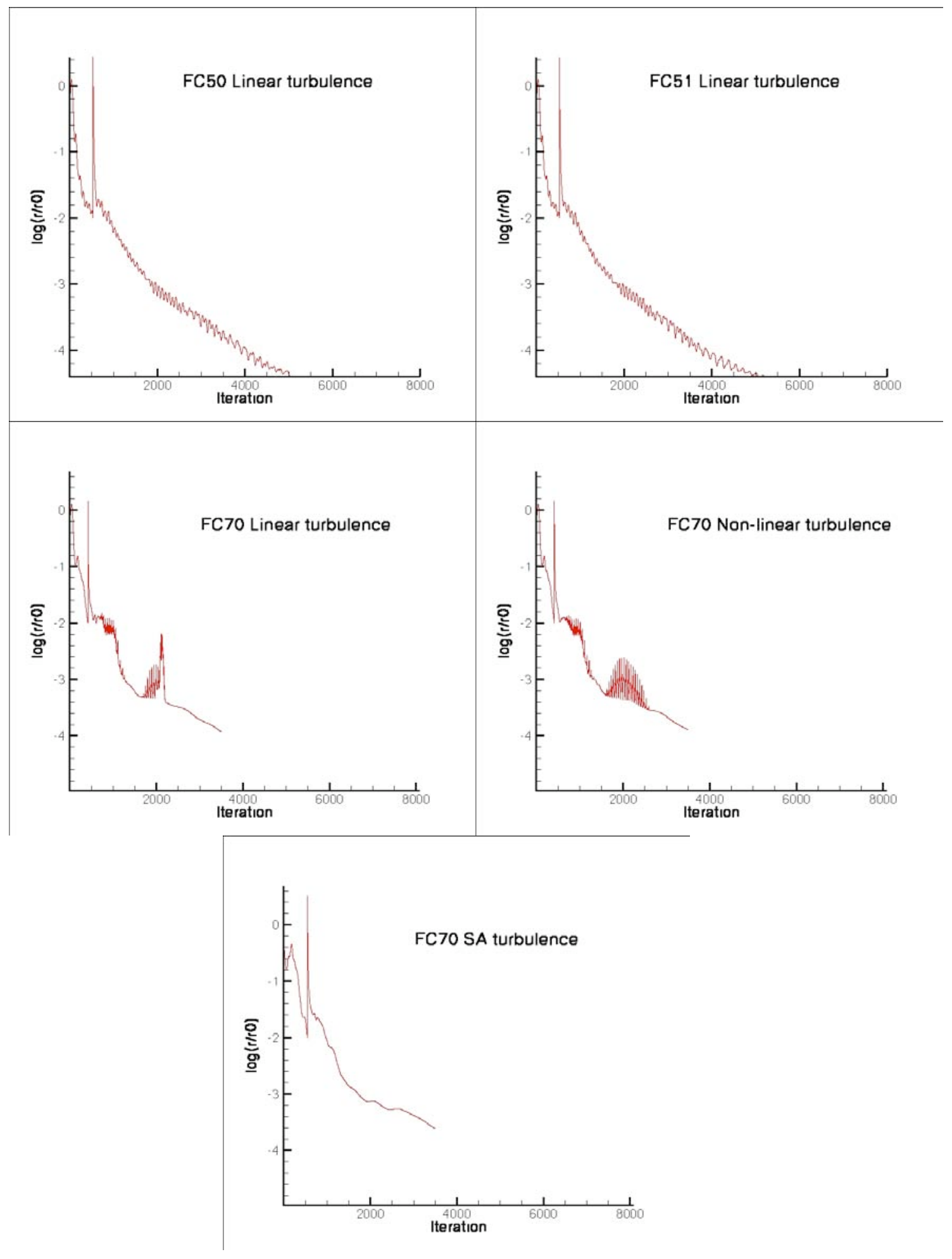

Figure A1. Concluded.

\section{Acknowledgment}

The authors gratefully acknowledge the support provided by Lockheed Martin Aeronautics Company Fort Worth in providing a refined iges geometry file and the parameter values of a generic engine that were 
subsequently used by facet members in their CFD studies; the geometrical work performed by Mr. Edward B. Parlette of Vigyan, Inc. in generating a series of unstructured, tetrahedral grids from the iges file, with the last one known as the base grid; and the $\mathrm{C}_{\mathrm{p}}$ layouts and computational support provided by Dr. Alaa Elmiligue of Analytical Services and Materials, Inc.

\section{References}

p 146.

${ }^{1}$ Bertin, John J.; and Smith, Michael L.: Aerodynamics for Engineers, Second ed. Prentice-Hall, Inc., 1989,

${ }^{2}$ Frink,N.T., Pirzadeh, S.Z., Parikh, P.C., Pandya, M.J., and Bhat, M.K.: The NASA Tetrahedral Unstructured Software System. The Aeronautical Journal, Vol. 104, No. 1040, pp. 491-499, October 2000.

${ }^{3}$ Lamar,J.E.; and Obara, C.J.: Review of Cranked-Arrow Wing Aerodynamics Project: Its International Aeronautical Community Role. AIAA Paper 2007-0487, To be presented at $45^{\text {th }}$ AIAA Aerospace Sciences Meeting and Exhibit, Reno NV, January 8-11, 2007.

${ }^{4}$ Lamar, John E., Obara, Clifford J.; Fisher, Bruce D.; and Fisher, David F.: Flight, Wind-Tunnel, and Computational Fluid Dynamics Comparison for Cranked Arrow Wing (F-16XL-1) at Subsonic and Transonic Speeds. NASA/TP-2001-210629, February 2001.

${ }^{5}$ Boelens, O.J.; Goertz, S.; Morton, S.A.; Fritz, W.; and Lamar, J.E.: Description of the F-16XL Geometry and Computational Grids Used in CAWAPI. AIAA Paper 2007-0488, To be presented at $45^{\text {th }}$ AIAA Aerospace Sciences Meeting and Exhibit, Reno NV, January 8-11, 2007.

${ }^{6}$ Pirzadeh, Shahyar Z.: Vortical Flow Prediction Using an Adaptive Unstructured Grid Method. Presented at RTO AVT Symposium on Advanced Flow Management; Part A - Vortex Flow and High Angle of Attack, Paper Number 13, in Loen Norway during May 7-11, 2001.

${ }^{7}$ Elmiligue, A.A.; Abdol-Hamid, K.S.; and Massey, S.J.: PAB3D Simulations for the CAWAPI F-16XL. AIAA Paper 2007-0491, To be presented at $45^{\text {th }}$ AIAA Aerospace Sciences Meeting and Exhibit, Reno NV, January 8-11, 2007.

${ }^{8}$ Boelens, O.J.; Spekreijse, S.P.; Sytsma, H.A.; and de Cock, K.M.J.: Comparison of measured and simulated flow features for the full-scale F-16XL aircraft. AIAA Paper 2007-0489, To be presented at $45^{\text {th }}$ AIAA Aerospace Sciences Meeting and Exhibit, Reno NV, January 8-11, 2007.

${ }^{9}$ Badcock, K.J.: Evaluation of Results from a Reynolds Averaged Multiblock Code Against F-16XL Flight Data. AIAA Paper 2007-0490, To be presented at $45^{\text {th }}$ AIAA Aerospace Sciences Meeting and Exhibit, Reno NV, January 8-11, 2007.

${ }^{10}$ Fritz, W.: Hybrid Grid RANS Solutions For The CAWAPI F-16XL. AIAA Paper 2007-0492, To be presented at $45^{\text {th }}$ AIAA Aerospace Sciences Meeting and Exhibit, Reno NV, January 8-11, 2007.

${ }^{11}$ Morton. S.A.; McDaniels, D.R.; and Cummings, R.M.: F-16XL Unsteady Simulations for the CAWAPI Facet of RTO Task Group AVT-113. AIAA Paper 2007-0493, To be presented at $45^{\text {th }}$ AIAA Aerospace Sciences Meeting and Exhibit, Reno NV, January 8-11, 2007.

${ }^{12}$ Goertz, S. and Jirasek, A.: Unstructured Steady/Unsteady Solutions with Edge for CAWAPI F-16XL at KTH/FOI. AIAA Paper 2007-0678, To be presented at $45^{\text {th }}$ AIAA Aerospace Sciences Meeting and Exhibit, Reno NV, January 8-11, 2007.

${ }^{13}$ Michal, T.; Oser, M.; Mani, M.; and Ross, F.: BCFD Unstructured-Grid Predictions On The F-16XL (CAWAPI) Aircraft. AIAA Paper 2007-0679, To be presented at $45^{\text {th }}$ AIAA Aerospace Sciences Meeting and Exhibit, Reno NV, January 8-11, 2007. 
${ }^{14}$ Davis, M.B.; Reed, C.; and Yagle, P.: Hybrid Grid Solutions on the (CAWAPI) F-16XL Using Falcon v4. AIAA Paper 2007-0680, To be presented at $45^{\text {th }}$ AIAA Aerospace Sciences Meeting and Exhibit, Reno NV, January 8-11, 2007.

${ }^{15}$ Karman, S.; Mitchell, B.; and Sawyer, S.: Unstructured Grid Solutions of CAWAPI F-16XL by UT SimCenter. AIAA Paper 2007-0681, To be presented at $45^{\text {th }}$ AIAA Aerospace Sciences Meeting and Exhibit, Reno NV, January 8-11, 2007. 